\title{
Exploring Young Adults' Understanding and Experience with a Digital Legacy Management System
}

\author{
Fabrício H. S. Pereira \\ Computer Science Department \\ Federal University of Minas Gerais \\ Belo Horizonte, Brazil \\ fabriciohsp@dcc.ufmg.br
}

\author{
Fernanda Tempesta \\ Computer Science Department \\ Federal University of Minas Gerais \\ Belo Horizonte, Brazil \\ fernandatempesta@dcc.ufmg.br \\ Raquel O. Prates \\ Computer Science Department \\ Federal University of Minas Gerais \\ Belo Horizonte, Brazil \\ rprates@dcc.ufmg.br
}

\author{
Caio Pimentel \\ Electronic Engineering Department \\ Federal University of Minas Gerais \\ Belo Horizonte, Brazil \\ zerocp@ufmg.br
}

\begin{abstract}
The current society produces and consumes large amounts of digital content, especially young people. Each person accumulates throughout their lives a set of digital items that will constitute their own digital legacy. Recently, a number of works that focus on post-mortem data and technology have been published. Our work adds to the existing body of work, and explores the perspective of Brazilian young adults between the ages of 18 and 24 on digital legacy management systems. We investigate how this public understands the new concepts introduced by this domain, and what are their attitude towards it based on their experience with the different roles offered by the system, namely the account owner, the trusted contact and the heirs. We selected the system Afternote to provide a context for our exploration. The first step in our study was to perform a systematic analysis of the system, followed by two user studies in which young adults explored and shared their views of the system, based on their focus on the role of account owner or trusted contact. Our results show that participants could understand the novel concepts introduced by Afternote, but some of the processes that would take place in the future represented more of a challenge. They believed the system was useful, but raised many issues and costs associated to its use. These results contribute to the ongoing research, evaluation and design of Digital Legacy Management Systems.

Index Terms-Digital Legacy; Death; Digital Legacy Technologies; Semiotic Inspection Method; SIM; Semiotic Engineering, Digital Legacy Management System, Digital Legacy Management Framework; DiLeMa Framework.
\end{abstract}

\section{INTRODUCTION}

An individual's digital legacy can be defined as the set of digital items accumulated throughout one's life. Digital items can be a personal photo, files containing user-generated material, accounts on different social networks, as well as emails or digital books [1], [2]. Nowadays, technology is so

The authors are grateful to CAPES and FAPEMIG for partially funding this research. present in people's daily lives that it includes even systems that support people in dealing with their own deaths or bereavement.

In recent years, research regarding technology related to death encompasses a broad range of issues related to death and mourning [3], and a large number of systems related to the topic have been developed [4], [5]. Although significant contributions have been made by researchers on aspects that vary from understanding users' needs [3], [6] to exploring new technologies that can support different aspects of death [7], there are still open questions that should be investigated [8], [9]. In this work, our focus is on Digital Legacy Management Systems (DLMS).

The Brazilian Institute of Geography and Statistics (IBGE) has published a recent report of a study conducted in 2016 [10] that shows that, in the last quarter of that same year, young adults (people between the age of 18 and 24) represented the Brazilian age group that used the Internet the most (which includes SMS, watching videos, voice/video calls and receiving/sending e-mails). Therefore, we can presume that this group is generating a large amount of digital items that in the future will comprise their digital legacy. In this scenario, these young adults represent potential future users of Digital Legacy Management Systems (DLMS). In this paper, our goal is to explore the perspective of these young adults regarding DLMS $^{1}$. Our investigation focused on two aspects: (1) how users understood the DLMS and the concepts introduced in this domain; (2) their experience related to their use of such

\footnotetext{
${ }^{1}$ This paper is an extended version of the paper intitled "Young Adult's Perspective on Managing Digital Legacy" published in IHC 2018 [11], in which the results of the first of the two studies described in this paper were presented.
} 
systems, taking into consideration the different roles they could take within the system (user, trusted contact or heir).

In order to collect data on the young adults' perspective, we interviewed them based on a presentation and their interaction with a DLMS. For this research we selected the Afternote system [12] for the participants' exploration. Afternote was chosen because it is a freeware system that offers a range of services associated to digital legacy management (e.g delivery of posthumous messages and registering wishes regarding social media accounts). To structure our analysis of the concepts presented in the system and the users' understanding of them, we chose to use the Digital Legacy Management - DiLeMa framework - a conceptual framework that represents the relevant dimensions in Digital Legacy Management Systems (DMLS) and that can be used in the design and analysis of such systems [13], [14].

To answer our first question regarding how users understood the concepts, we first performed a systematic analysis of the Afternote System using the Semiotic Inspection Method [15] in combination with the DiLeMa framework [13] to describe the system. Next, we conducted a user study with 10 participants. The study involved a guided exploration of the system, followed by an interview about their understanding of the system and how they felt about using it. We then contrasted their answers with the analysis conducted of the system.

The interview questions regarding their experience with the system were used to answer our second research question. In this case, participants explored the system as account owners (those who make decisions about their own digital legacy). We also conducted another user study in which we explored with 7 participants their experience as trusted contacts (the one who is appointed by the account owner to inform the system of his/her death and act as a representative to carry his/her wishes within the system). In both studies we asked them about how they would feel as heirs of someone else's digital legacy.

Our results show that participants were able to grasp the meaning of the new concepts introduced by Digital Legacy Management Systems, represented in DiLeMa. However, understanding processes that would take place in the future represented a challenge to some of the participants. Their experience with a DLMS showed that young adults do not believe their digital artifacts are of much value to others, but they consider that some of it could have a sentimental value to people close to them. Nonetheless, in general, they perceived the system as useful. They pointed out the emotional and interactive costs in dealing with the system. The results point to open issues on the post-mortem technology research, and also aspects that could be considered in the project and analysis of such systems.

In the next section, we present some of the related works that tackle research on technology associated to death. The following section, presents the methodology we have adopted in this paper. Then, in the next two sections, we present the results and analysis to each one of our research questions. Finally, we discuss our results and future directions of our research.

\section{RELATED WORKS}

Research associating technologies and death has grown in the scientific community of Human-Computer Interaction. In special, in the Brazilian community the topic was brought to attention by the Grand Research Challenges in HCI in Brazil (2012-2022)(GranDIHC-BR) [16], [17] and the Grand Research Challenges in Information Systems in Brazil (20162026) (GrandSI-BR) [18]. One of the effects of this growth was the proposal of systems that support different aspects of death, ranging from systems that help a person plan aspects related to their own death to systems that help grieving people honor a deceased person. In this section, we present some of the different types of systems found in literature and briefly describe the research associated with them.

Some systems are designed for planning and usually they focus on allowing users to record their wishes and relevant information regarding their own death, funeral and memorial (eg. Everplans [4]). Digital Memorials create a virtual place for people to remember and mourn a dear one who has died [19]. Research on Digital Memorials includes requirement elicitation for such systems [19], as well analysis of different cultural aspects related to practices and rites associated to death [20]. In 2017, de Campos et al. [21] investigated design opportunities for digital memorials through a focus group with experts and researchers using Facebook memorials to base their discussions. The authors discuss desired features of memorials such as: showing who is the heir responsible for the memorial account, the visibility of messages in relation to mourning, the formation of groups, as well as issues regarding notification, among other aspects.

Digital Posthumous Communication Systems allow users to write digital messages that will only be sent to their recipients after the senders' death [22], [23]. These systems can be classified into two categories, according to the moment when they are sent. In the first category, users define settings in the system such that the system will send messages on behalf of the user for a period of time after their deaths (e.g. send a friend birthday messages every year). Often the messages are sent as if it were being sent from the user at that moment. An example of such a system is DeadSocial [24]. Powell et al. [22] investigated what people thought or would feel if they were recipients of such messages. In the second category, users writes messages to be sent to specific recipients (once) a short period after their death, such as a posthumous e-mail [23]. Pereira et al. [23] analyzed two of these systems and discussed how designers expressed in the interface the future effects of configuration, so that users could understand at decision time the impact of their configuration settings.

Digital Legacy Management Systems (DLMS) allow users to define the destination to be given to (part of) their Digital Legacy [5], [13]. It is worth noting that DLMS often allow messages to be included in the users' digital legacy to be sent posthumously to others. Although they might cover the functionality of Digital Posthumous Communication Systems, they go beyond messages, and usually include other digital items, 
such as photo or other files. As people nowadays generate and store a great deal of digital artifacts, some of the questions being researched are: (i) what would people want to leave for future generations [25] and (ii) how would people like to transfer these artifacts on to family, friends or institutions [8]. In this direction, recently, Pfister [26] investigated how users transfer official information, that is, information that would be needed to manage individual or family life in business or government processes. As a result, the author identifies several challenges related to storing sensitive data in the cloud [26].

Finally, some systems include some functionalities related to the different types of systems described. In this direction, some authors have denominated Digital Heritage Management Platforms (PGHD) [5] systems that encompass what we have defined as DLMS, online memorials and information for creating future avatars representing users.

In this article, our focus is on DLMS, but different from the cited works, we explore how aspects related to the decisions involved in this management are represented in the system and how they are perceived by young adults. In addition, we explore with users their insights about the role of users, heirs or curators.

\section{TheORETICAL FoundATION}

In this section, we present the Digital Legacy Management (DiLeMa) Framework and the Semiotic Inspection Method, and how they were used in this paper together to perform the analysis conducted.

\section{A. Digital Legacy Management (DiLeMa) Framework}

The Digital Legacy Management (DiLeMa) framework ${ }^{2}$ is a conceptual framework that aims at identifying relevant concepts and processes that should be considered in the design, evaluation and research of DLMS [13], [14]. DiLeMa presents 6 dimensions, each one representing a relevant concept in DLMS. Fig. 1 depicts an overall view of the framework. The framework also includes the different strategies designers can adopt regarding digital legacy management. Next, we describe each dimension, the possible values the dimension can take, as well as the overall strategies.
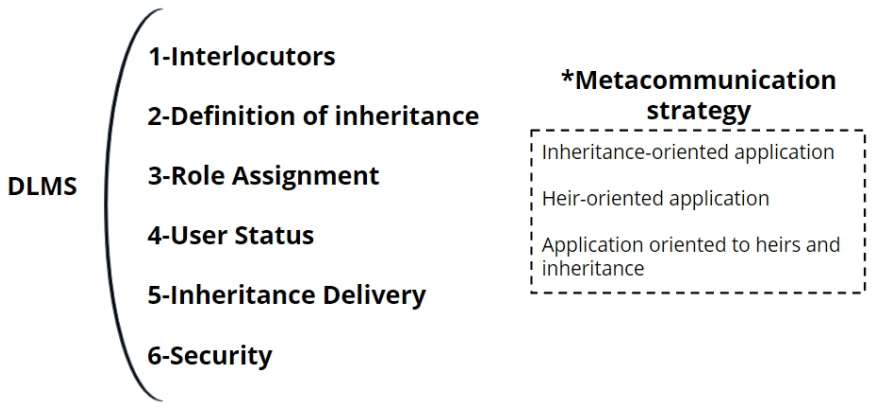

Fig. 1. DiLeMa with all its dimensions.

\footnotetext{
${ }^{2}$ In this article, we use the acronym DiLeMa for the first time to name our conceptual framework presented in other studies [13], [14].
}

1. Interlocutors: This dimension describes the roles that different people can take on in a DLMS. In this work, whenever we refer to the user of a DLMS we are referring to a user who have created the account on a system for the purpose of managing his/her Digital Legacy. Therefore, users are people who create accounts in the system (account owners) and determine the destination of their digital assets after their death or inactivity in the system. Defining the future of their digital assets involves determining who will receive which of their assets once they have passed away. The people who users nominate to receive one or more of their assets are their heirs or beneficiaries. Trusted contacts are people named by users to represent them within the system once they are gone. Finally, the system itself has an active role as an interlocutor because it sends messages and/or instructions to other interlocutors on behalf of the user. These interlocutors can be seen in Fig. 2.

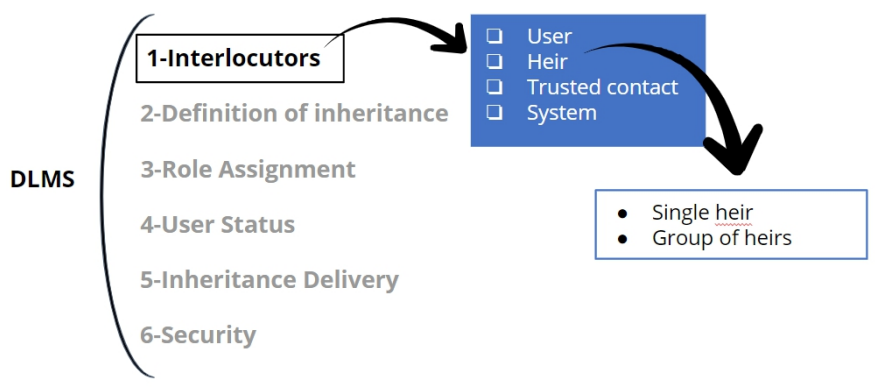

Fig. 2. Interlocutors in DiLeMa Framework.

2. Definition of inheritance : Users define what digital assets will be sent to which heirs, as shown in Fig. 3. In a DLMS, digital assets are all of the users digital possessions that they wish to make decisions regarding their destination within the system. The heirs association refers to specifying at some point which heir will receive a specific digital asset of the account owner.

There are three different approaches regarding the digital assets the system manages. The first one, the system already contains users' assets and allows them to define their future. In the second, the goal of the system is to allow for the management of digital legacy and users have to upload any asset they want to make decisions upon into the system. Finally, in the third approach system stores information or some access right to assets stored in other systems.

3. Role Assignment: the user is responsible to assign people to take on the roles related to their own legacy (i.e., trusted contacts and heirs), as depicted in Fig. 4. The DLMS can define whether this assignment is made by request (the user invites the person to take on a role, and the person can accept or decline it) or by nomination (the user nominates a person who is informed by the system of the role he/she is expected to take, either at the moment of nomination or after the user becomes inactive).

4. User status: DLMS define a user status to determine the moment when users' decisions must be followed. An active 


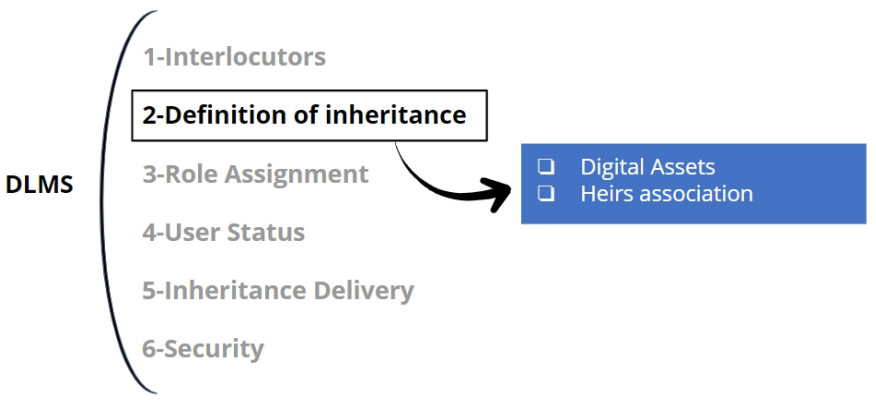

Fig. 3. Definition of Inheritance in DiLeMa Framework.

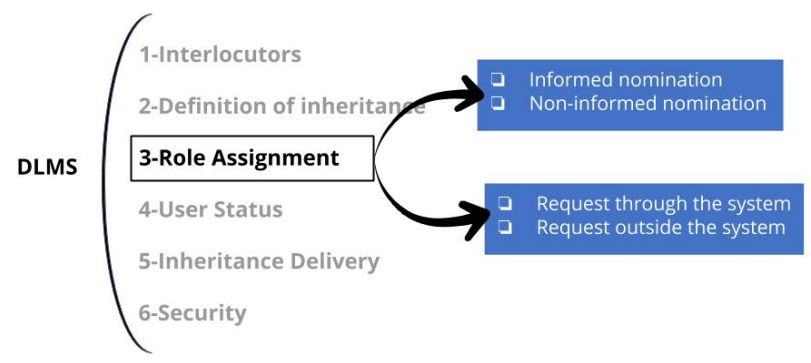

Fig. 4. Role Assignment in DiLeMa Framework.

status means the user is using his/her account, whereas an inactive status means that the system understand the user will no longer use his/her account, and it is time to execute the decisions determined in the system. This is the DLMS process that defines the user status, active (still using his account) or inactive (inheritance must be released). There are different triggers that may lead the system to change users' status, such as being notified by a trusted contact of the user's death, or taking into account the users' downtime.

Independently of the trigger used to change the status, once it is activated the users' status is usually changed to uncertain and the verification process starts. It involves trying to contact the users for a period of time or confirmation period. If the user responds, his/her status is reset to active. If the user does not, the system may conclude that the user is inactive or proceed to another verification step. Systems in which trusted contacts are registered, include a step in which it asks them about the user's status. If they inform that the user is active, then the user's status is also reset to active. If they fail to respond, or inform that the user is inactive, then the user's status is changed to inactive. Fig. 5 illustrates the user status dimension.

5. Inheritance Delivery: Once the user confirms the user's status as inactive, then it proceeds to follow users decisions regarding his/her digital assets (see Fig. 6). The framework describes 3 different approaches to delivering users' assets to their heirs. In the first the system delivers users' assets directly their heirs' e-mails. This approach is usually adopted

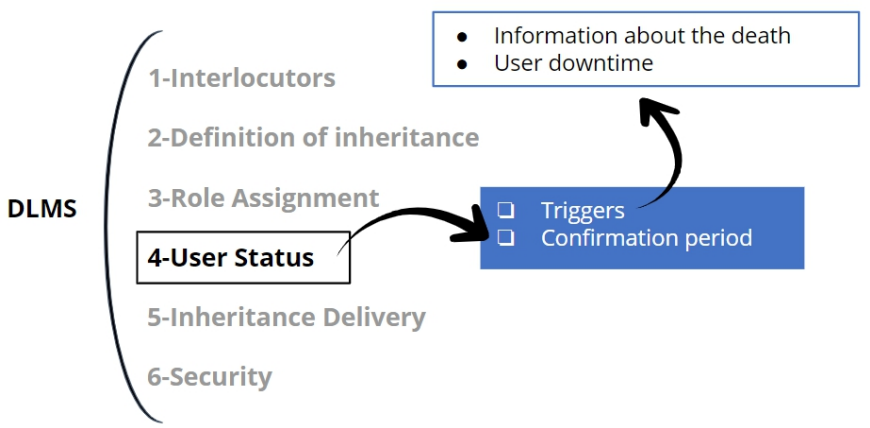

Fig. 5. User Status in DiLeMa Framework.

by systems that limit digital assets to text messages or text messages with limited types of files. In the second approach the system sends the heirs a message containing an access link and instructions, so that they can download (a copy of) the user's digital assets left for them. Finally, the third approach is when the system requires the heirs to create an account in the system in order to have access to the digital assets destined to them.

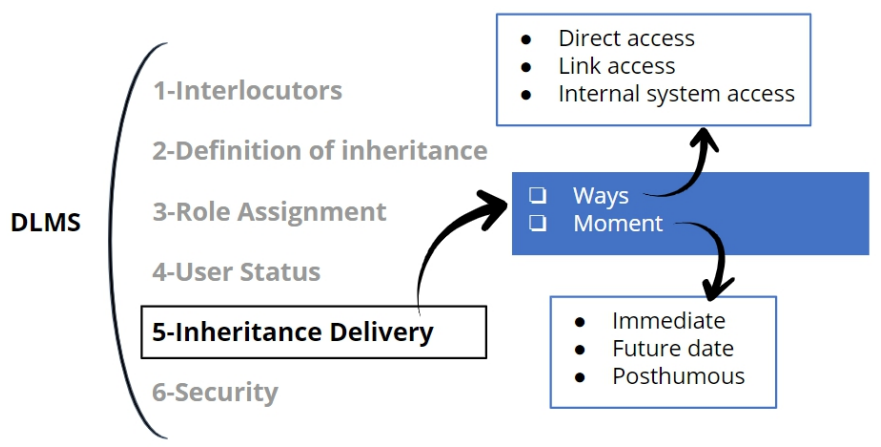

Fig. 6. Inheritance Delivery in DiLeMa Framework.

Security refers to mechanisms and resources that DLMS must adopt to maintain the confidentiality of inheritance and the privacy of the account owner (see Fig. 7). In this dimension two distinct aspects are involved: authentication of interlocutors (confirmation of the right of access to the user's information by another interlocutor); and data security (mechanisms that ensure the security of data handled or stored in the DLMS).

The process of authenticating interlocutors is associated to verifying whether beneficiaries and trusted contacts are who the user intended them to be. The systems that require trusted contacts to be defined outside the system, necessarily need an authentication process to guarantee that they have been authorized by the user (no longer available) to act as his/her trusted contact. The user is supposed to give the appointed trusted contact an activation code generated by the system, that has to be used by him/her to inform the system of the user's death.

Regarding heirs, the system may include a security check to confirm that the people being given access to the inheritance 
are who they should be. Then, when the user is deemed inactive, the heir receives an e-mail message containing the download link for the digital assets destined to him/her, and a confirmation code is sent to his/her phone. In order to access the link, the beneficiary must insert the confirmation code sent to his/her phone, for example.

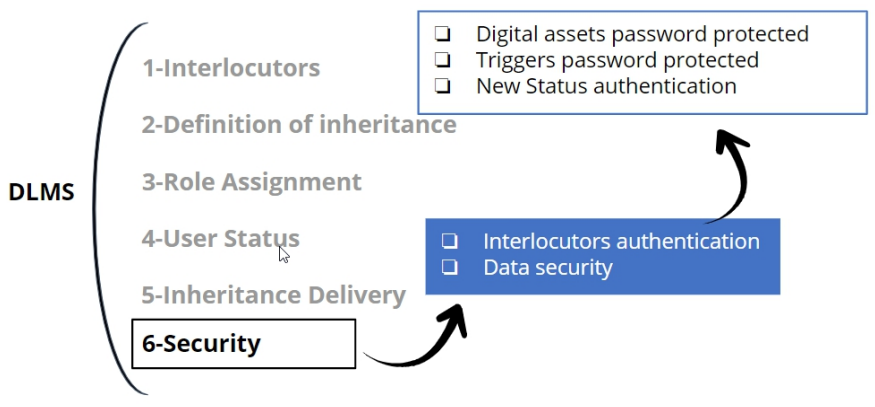

Fig. 7. Security Mechanisms in DiLeMa Framework.

Metacommunication strategies represent the strategies designers of DLMS choose to present users regarding how to go about managing their digital assets (Fig. 8). The strategies identified are: heritage-oriented strategy (the digital assets are the focus, and for each one (or set) users make decisions on how it will be distributed); heir-oriented stategy (users focus on who they want to nominate as heirs, and then decide which digital assets each one will receive); mixed application - inheritance and heirs (designers combine the two previous strategies, often leaving it to the user to decide their preference on which focus to take when organizing their own legacy).

\section{*Metacommunication strategy}

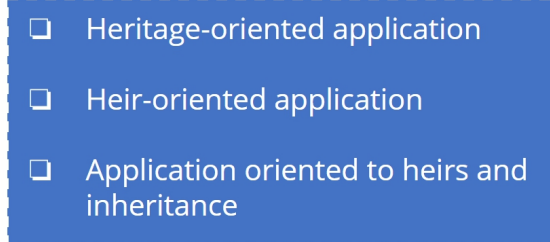

Fig. 8. Metacommunication strategies that represent the focus of the digital assets management in the DLMS.

\section{B. Semiotic Inspection Method - SIM}

Semiotic Engineering [27] perceives a system's interface as a designer-to-user communication act, in which designers convey to users who they believe users are, what they could or should do with the system, and how to interact with the system to achieve their goals. Users grasp this message as they interact with the system. Among the existing methods based on Semiotic Engineering, the Semiotic Inspection Method is a method that supports a Semiotic Engineering expert to examine and reconstruct the intended designer-to-user message being conveyed through the interface [15], [28]. To do so, SIM requires the analyst to perform a segmented analysis of the communicative aspects of the interface, and then proceed to contrasting the results and generating an integrated analysis. Before we can explain the steps of SIM, we present some basic concepts from the Semiotic Engineering theory that are necessary to the understanding of the method.

The designer's message is comprised of signs - that is, anything that someone can take to stand for something else in some respect or situation. Semiotic Engineering classifies interface signs into three categories: static, dynamic and metalinguistic [28].

Static signs are those that can be interpreted independently of causal and temporal relations, and can be taken to represent the state of the system (e.g. a toolbar or set of menu options). Dynamic signs, on their turn, are bound to causal and temporal relations, and represent the interaction itself (e.g. the system's behavior that follows when a user clicks on an interface button). Finally, metalinguistic signs are those that allow designers to explicitly explain the static and dynamic signs in the interface - the meanings that have been encoded and how they can be used (e.g. a tooltip associated to a button, or an instruction on how to fulfill a field).

In order to apply SIM, the analyst must first perform an informal inspection of the system, that allows him/her to define the focus and scope of the analysis, and to elaborate an inspection scenario. After the preparation, the analyst proceeds to perform five steps. The first three steps require the analyst to separately inspect the communication being conveyed through each class of signs in the following order: metalinguistic, static and dynamic. Each step represents the inspection of that sign class, and the analyst reconstructs the the designer-to-user message. This message can be paraphrased as:

"Here is my understanding of who you are, what I've learned you want or need to do, in which preferred ways, and why. This is the system that I have therefore designed for you, and this is the way you can or should use it in order to fulfill a range of purposes that fall within this vision.” [27, p. 25].

The analyst uses this paraphrase as a template, identifying potential communicative breakdowns and problems users may experience regarding those signs.

In the last two steps, the analyst proceeds to compare and synthesize previous results. In step 4, the analyst contrasts the reconstructed versions of the designer's message, analyzing (in)consistencies, patterns and relations among them. Finally, in step 5, the analyst generates a unified designer-to-user message (using the paraphrase template) and assesses the costs and benefits of the identified communicative strategies.

In this work, SIM was combined with the DiLeMa framework. The goal was to analyze the designer's metacommunication message, explicitly in the reconstruction steps what was being conveyed regarding each of the framework's dimensions. Next, we present an overview of the entire research process as well as the studies done with the young adult participants. 


\section{Methodology}

In this work, our goal is to explore young adults' perspective regarding Digital Legacy Management Systems. However, in our experience, not many young adults are users of or even familiar with DLMS. Thus, for our research we decided to interview them based on the presentation and exploration of an existing DLMS.

In order to select a system, we performed an informal inspection of the systems listed in the The Digital Beyond [4] list. As this is a well-known list of online services related to digital death, afterlife and memorialization. From the list, we selected the system Afternote to carry out our exploratory study (see Fig. 9). The reasons for this choice were (i) access to the system is free; (ii) it includes management of digital legacy services (among others); (iii) an initial evaluation of the system indicated that all features of interest worked as described $^{3}$.

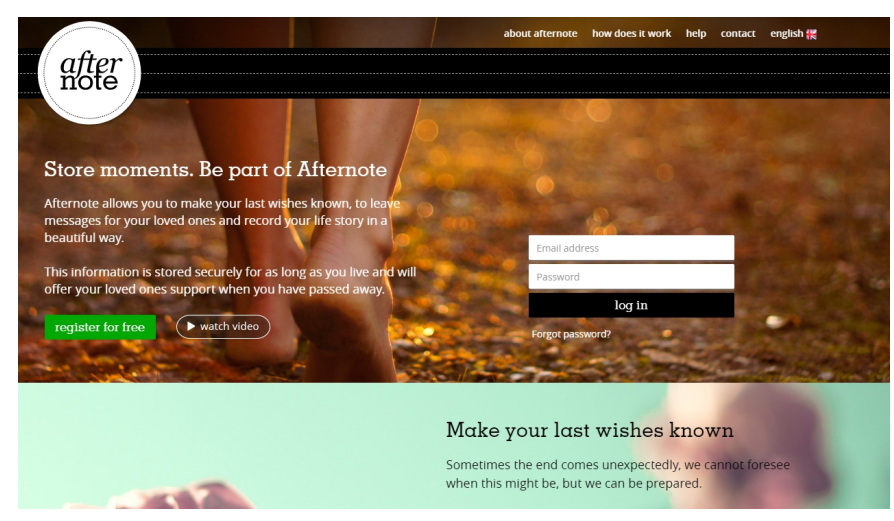

Fig. 9. Afternote homepage. Image taken from site: https://www.afternote.com/dashboard.

Once the system was selected, our first step was to perform a systematic analysis of the system, using the Semiotic Inspection Method (SIM) (explained in subsection III-B). The goal with the analysis was twofold. First of all, it allowed us to have a thorough understanding of the system, and how it worked. This understanding was necessary to be able to define the scope, presentation and exploration for our study with the young adults. Second, we wanted to investigate how these young adults understood the concepts introduced by DLMS. Therefore, we generated a formal analysis and description of the system that could be used to contrast and discuss the participants' understanding. Our goal in conducting the analysis was not only to understand the general design and interactive decisions, but also to generate a detailed description of the concepts and aspects specific to the digital legacy management domain ${ }^{4}$. Therefore, we used the framework

\footnotetext{
${ }^{3}$ Some of the systems that offered a free or trial version did not allow access to all of the features indicated that would be of interest

${ }^{4} \mathrm{We}$ consider general design and interactive decisions the definition of the designers intention with the system, as well as features that are common in other domains, such as registering and creating a profile. Concepts specific to the domain of interest include defining heirs or writing messages to be delivered post-mortem.
}

DiLeMa (explained III-A) in combination with SIM, to generate the description of specific aspects regarding digital legacy management.

We conducted two studies with young adults. The first one explored their perspective as account owners (and we will also refer to them as users) of the system, that is the person who uses the system with the goal to make decisions about the future of his/her digital legacy after his/her death. The second study investigated their perspective as the users' trusted contact, that is the one the account owner nominates as responsible for representing them to the system after their death, usually involving informing the system of the user's death, as well as acting on their behalf. Both studies involved a presentation/exploration of the system, and an interview about their views of the system. In the two studies, the interview also included one or more questions about how participants would feel as someone's heir. For our studies we created a test account, that could be used without requiring any personal or private information from the participants. The overall view of the methodology can be seen in Fig. 10.

The first study, involved a brief explanation of the system, a set of 4 tasks using the system in the role of account owners. The tasks included nominating a trusted contact (denominated trustee in Afternote), including information in their timeline, writing a message to be delivered post-mortem and making decisions about a social media account. After their interaction with Afternote, we conducted an interview that included questions about their understanding of the system and their expectation of how it would work if it were informed of their death, as well as of their experience using the system. The study sessions were conducted in May 2018 with 10 participants.

For the second study, we simulated the death of our 'test account user'. Once the system updated the status of our test user to deceased, the trustee was expected to interact with the system. As the trustee's actions could only be performed once, we performed the actions that we wanted to explore and recorded the interaction with the system in video. In this study, participants did not interact with the system. Their exploration was based on a guided tour by the researcher conducting the session. The tour included an explanation about the system in general, and of the many interfaces that would be presented to a trustee, as well as watching videos of a trustee's interaction with the system. Based on this exploration, an interview was conducted in which participants were asked questions about how they would feel about a role as someone's trustee. The study sessions were conducted in December, 2018 with 7 participants. Before the sessions, we conducted three pilot tests to adjust the study processes.

To explore the research question regarding users' understanding of DMLS, we used data collected from systematic analysis and from responses from user study 1 participants'. The SIM analysis combined with DiLeMa allowed for a detailed description of how are the designers decisions regarding the DLMS dimensions. In user study 1, the first part of the interview conducted focused on how participants 


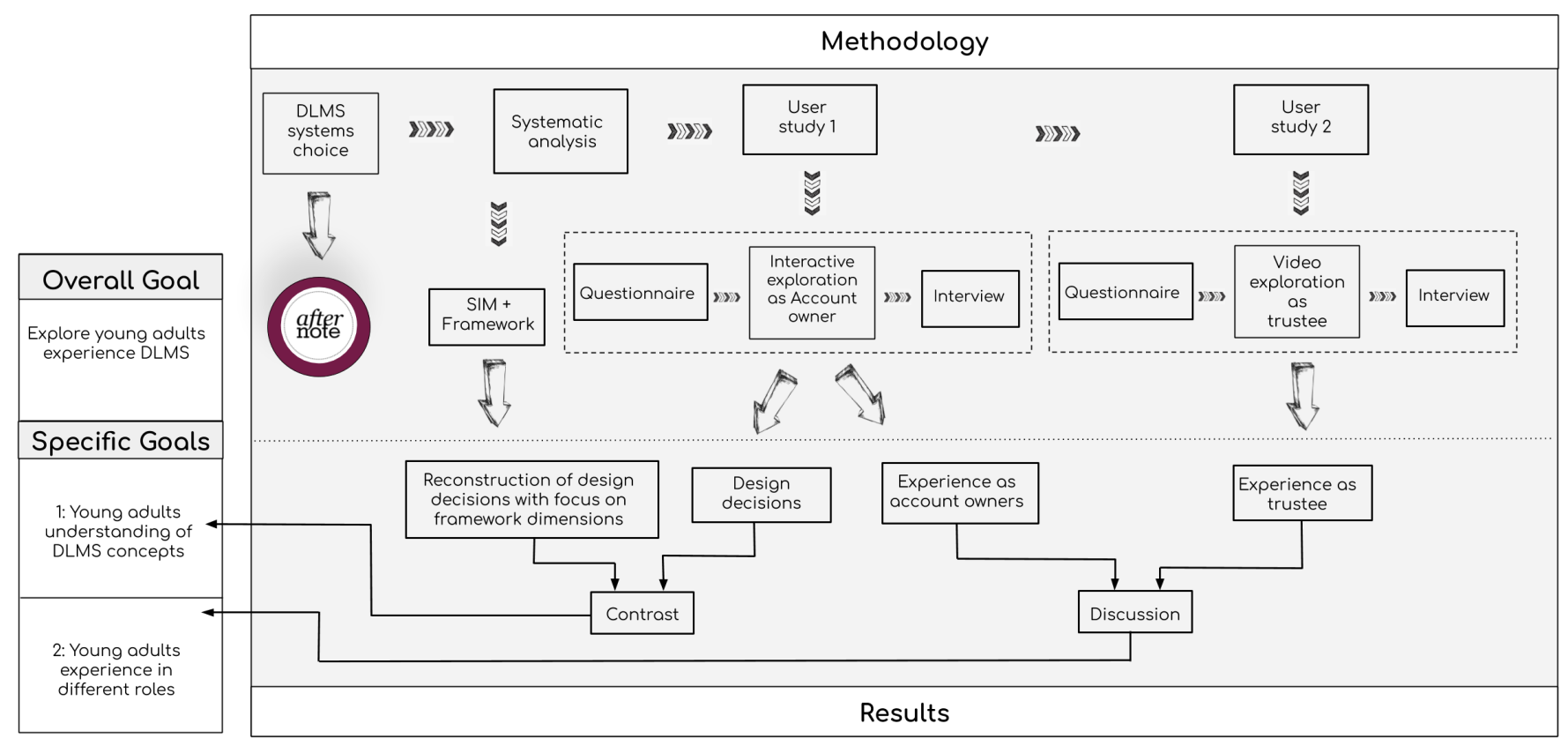

Fig. 10. Overview of the methodology adopted.

had perceived the concepts involved in the system, such as which were the roles defined in the system (e.g. user, trustee, heir), what digital artifacts can be left to others through the system, how would they be delivered through the system among others. We contrasted the responses to these questions, to the detailed description generated and analyzed whether users had understood the new concepts introduced by DLMS and described in DiLeMa dimensions, as well as how it would work in the future based on users decisions (explored in the systematic analysis through dynamic signs analysis of SIM). Notice that in the 2nd interview we did not explore their understanding of the DiLeMa dimensions, as participants were exploring the trustee's perspective, and could not interact with the system directly.

Regarding the experience users had with the system, our goal was to explore the perspective that young adults had of the different roles users could take in the system: account owner, trusted contact and heir. Thus, we contrasted their views regarding the roles they took in the exploration - account owner (study 1) and trustee (study 2). The role of heir was only explored in the interview, in both studies. In the remainder of this section, we present in more detail the studies conducted.

\section{A. User Study 1 - Account Owner Perspective}

The investigation of young adults' perceptions about Digital Legacy Management on a user's perspective was conducted on the interaction with Afternote in May, 2018. The study consisted of three steps: (i) survey of users' profile by the application of a pre-test questionnaire; (ii) Afternote exploration based on the execution of four selected tasks focused on the management of the Digital Legacy; (iii) interview about users understanding of and experience with Afternote. Ten young adults with ages varying from 18 to 24 , five males and five females have participated in the test. Only one participant has a university degree, the others are undergraduate students in different fields. More specifically, 8 participants from exact sciences (7 in courses related to Information Technology), 1 participant from humanities and 1 participant from biological sciences.

All participants had already used cloud shared service systems (e.g. Google Drive, DropBox, etc). Participants reported sharing different types of digital content, such as photos (8), videos (8), different files (9), music (7) and e-books (3). All of them are users of social media: Whatsapp (10), Facebook (8), Youtube (8), Instagram (4), Telegram (4), Linkedin (4), Pinterest (3), Snapchat (2) and Twitter (1). About the DLMS experience, users were asked if they had already thought about what would happen to their data and digital accounts when they died. Of the 10 participants, 6 said they had never thought about it, 3 said yes, and 1 of them was not sure. When asked if they had ever configured settings related to the future of their digital assets in any system, 8 answered that they had not and 2 were not sure if they had ever done such configuration or not. Only one participant had heard of systems that allow sending digital items to other people in the future. Eight of the young adults said that the existence of DLMS was novelty to them, and one participant was not sure if he had heard about it before.

The exploration of Afternote ${ }^{5}$ was conducted in individual

\footnotetext{
${ }^{5}$ The goal of the research and how the exploration would be conducted was explained to participants, and they signed a consent form. A test account was created and used for the research. The scenarios for the exploration were fictitious and all input information requested by the system during the interaction included data was included in the description of each task.
} 
sessions. First we briefly described Afternote to the participants, and they were asked to freely explore the system for a period of 3 to 5 minutes. Then they were given a set of 4 tasks to perform (one at a time) within the system. For the tasks, a scenario was presented to them, describing a situation in which, motivated by the death of a friend, the participant decides to think about the destination of his own digital assets. The tasks requested were: (T1) to name a person to be responsible for informing Afternote about the participant's "death" (in the future); (T2) to include an event in the timeline (in the system), containing a photo and a comment; (T3) to create a message intended for a friend to be delivered posthumously; (T4) to associate instructions about what should be done in regards to their Google Account in the future.

After each participant interacted with the system, an interview was conducted. The first part of the interview focused on their understanding about the system. Without mentioning directly the dimensions of the framework, we asked them what they understood about the underlying concepts presented in the system. The questions included: who is involved in the management of a legacy in the context of Afternote; which digital assets could be stored and managed in this system; how they would describe the process of inviting a trusted contact; how they understood the system would deliver their assets to nominated heirs and if they trusted that their assets would be delivered according to their wishes.

The second part of the interview focused on their experience with the system, and perception of DLMS in general. They were asked whether they had a good grasp of the digital assets they currently possessed; if they considered their assets would have any value (emotional or financial) to others; if they had ever thought about the future of their digital legacy before; how they would feel in organizing their digital assets to be delivered in the future to an heir; how would they feel if they received this kind of inheritance; and whether they would consider using a system like Afternote. The interviews were conducted in Portuguese (participants first language), audio recorded and later transcribed for analysis. A thematic analysis was performed by one of the authors and discussed with the others. The average length for the process of system exploration and each interview were about 1 hour.

\section{B. User Study 2 - Trustee Perspective}

In study 2, seven young adults participated: three males and four females, all students ( 6 undergraduate and 1 graduate student), with ages ranging from 18 to 24 years. As in study 1 , the second study involved the same 3 steps: (i) a survey of the participants profile; (ii) exploration of Afternote system in the trustee's perspective, and (iii) interview about their perspective of the trustee's perspective. All participants were explained the goals of the study, how it would be conducted, which data would be collected and chose to sign a consent form agreeing to participate in the research.

All participants stated they used cloud shared service systems with shared files through them. Only one user stated to never having shared a file. Participants reported storing different digital content: photos(7), videos(7), miscellaneous files(7), songs(3) and e-books(3). All participants are users of one or more social network systems: Facebook (7), Whatsapp (7), Instagram (5), Linkedin (3), Twitter(3), Google+(1), Youtube(6), Telegram (3) and Pinterest(3). Participants were asked if they had ever thought about the future of their digital assets after they died, only 2 stated to have thought about it. About having configured settings in their accounts regarding inactivity, 6 stated they had done nothing of sorts, and one stated not to be sure. Of the participants 4 said that they had heard about DLMS and 3 said they had not. None of them had ever acted as a trusted contact in any DLMS.

In this study, it was not feasible to have the participant interacting directly with the system, as it would require the creation of one test account per user, to guarantee the same interaction conditions for each participant. Therefore, the exploration step involved going through the homepage, and logging into a user account and explaining the system, based on a script that had been previously prepared. In order to explore the trustee's perspective, three videos were recorded of the interaction of a test trustee in our test account. The first video showed a trustee receiving a request from the user through a message sent by the system to become the user's trustee. The second video showed how a trustee would inform the system of the owner's death and request that the account be unlocked. Finally, the third video, showed the trustee accessing the user's unlocked account to check on his/her wishes and instructions.

After this exploration, during which participants could ask questions related to the system and how it worked, an interview about their perception of the trustee's perspective was conducted. Young adults who participated in the study were asked if they would accept be a trustee for someone (whom and in which conditions); if they would feel comfortable in such role; if they believed that a request to the intended trustee to take the role was necessary; if they would be comfortable saying "no" to such request; if they would accept the role as trustee, if they would feel obligated to honor all of the deceased wishes; how they would feel to perform the expected actions (inform the system of the death, unlock the system, etc); if they would trust the system would deliver all the inheritance, if they would worry about any security aspect. The interview also included questions about how the participant would feel being someone's heir, if they had ever thought about their digital legacy before, and if they thought in uncommon to think about it.

Different from study 1, this study was conducted by two of the authors, separately in two distinct cities. In order to try and create a consistent application of the study, a detailed script was created for the study, and a pilot study in which both researchers participated was conducted and discussed between them before they apply the study individually, each one conducted an individual pilot study. Five sessions were conducted in Fortaleza, Ceará state, Brazil. Four of them were performed in a co-working space inside Rio Mar Shopping mall and the fifth in a private home. The sixth and seventh 
interviews were conducted in the participant's homes, in the city of Lavras, Minas Gerais state, Brazil. All sessions were conducted in December, 2018. The average length for the process of presenting the research, exploration of the system and interviews was about 40 minutes in Study 2.

\section{RESUlts - UndeRstanding OF NEW DLMS CONCEPTS}

In these next two sections we present the results of our analysis. As mentioned, our goal was to analyze two different aspects regarding young adults' perspective of DLMS. The first one was how they understood the novel concepts introduced by the domain, and the second was their experience as owners and trustees within the system.

In this section we present our results and discussion regarding our first issue. In order to do so, we have contrasted the results of our SIM analysis with the study 1 participants responses to the first part of their interview about the system. The results of the SIM analysis combined with the framework provide an account of the designer's decisions regarding the dimensions being conveyed to users through the system. By contrasting it with the users understanding we generate indicators if designers of the Afternote in particular were able to successfully transmit to users their intended meaning (i.e. system has high communicability), and users views or challenges in grasping the novel concepts introduced by the DLMS domain.

Next, we present the results generated by our SIM analysis, followed by users views on the concepts discussed in the interview with participants of Study 1 and finally, we discuss the contrast about the intended and received meaning of these new concepts.

\section{A. SIM Analysis}

In this work, the SIM analysis in combination with the DiLeMa framework of Afternote was carried out by two researchers individually. Both evaluators had already applied SIM to other systems at least once. And then, the individual results were discussed and a consolidated analysis report was generated. The analysis was performed during the month of September, 2017. The main points of the metamessage generated with focus on the description of the DiLeMa framework dimensions are presented following.

Afternote is intended for people anywhere in the world who speak English (or Dutch), who use social networks and who care about the future of their data. Afternote users want to register their last wishes, leave farewell messages to their loved ones to be sent after they die, manage their Digital Legacy on social media and record their life history through a timeline. In addition, they want to store personal information about themselves and their family in their profile and all this in a secure way (Fig. 11).

The bucket list is intended for users to register goals they want to achieve and set a date by which they wish to have completed it (Fig. 12). For each goal reached, the user can add the date, photo and description of this goal. Users can

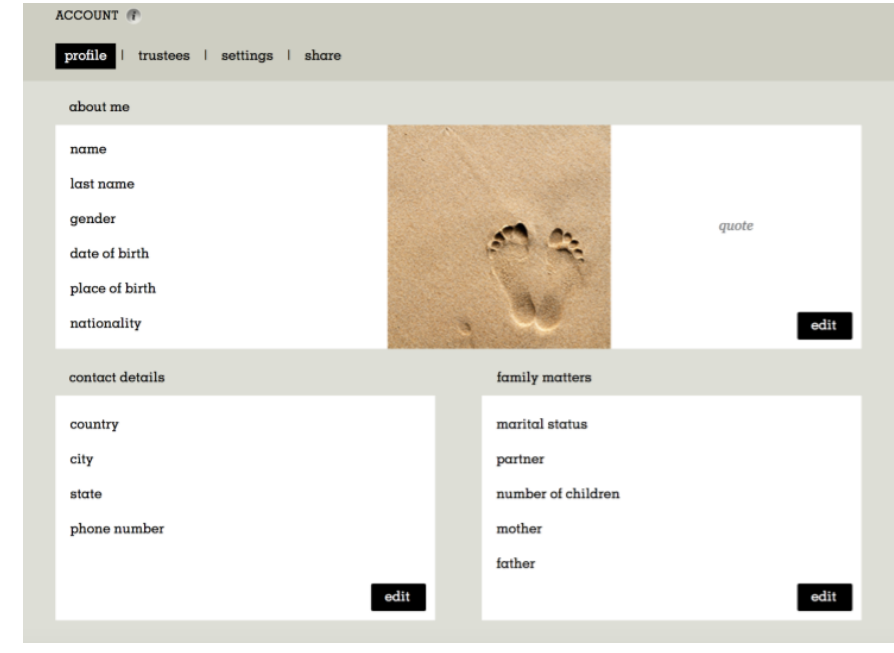

Fig. 11. Afternote account page. Image taken from site: https://www.afternote.com/Account/profile.

also keep a timeline with important moments and events of their life year by year, beginning with their birth, and can add photos or messages as well (Fig. 13). Finally users may write (and modify or delete) messages to their loved ones to be sent posthumously (Fig. 14).

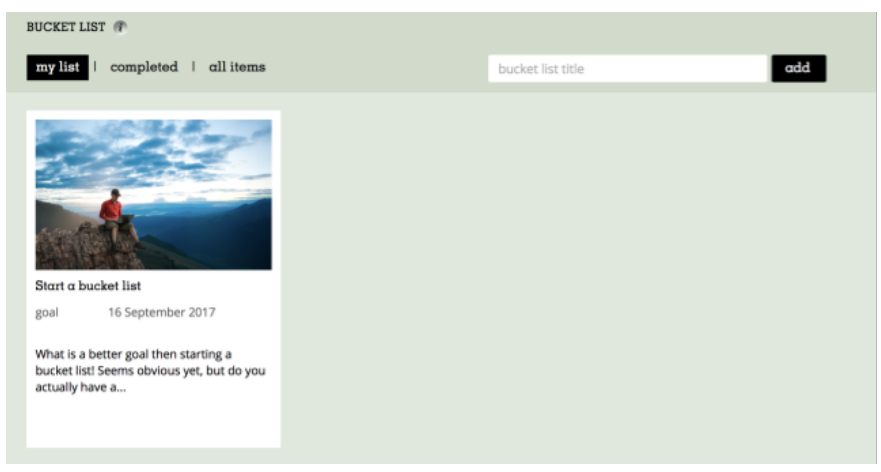

Fig. 12. Afternote bucketlist page. Image taken from site: https://www.afternote.com/bucketlist.

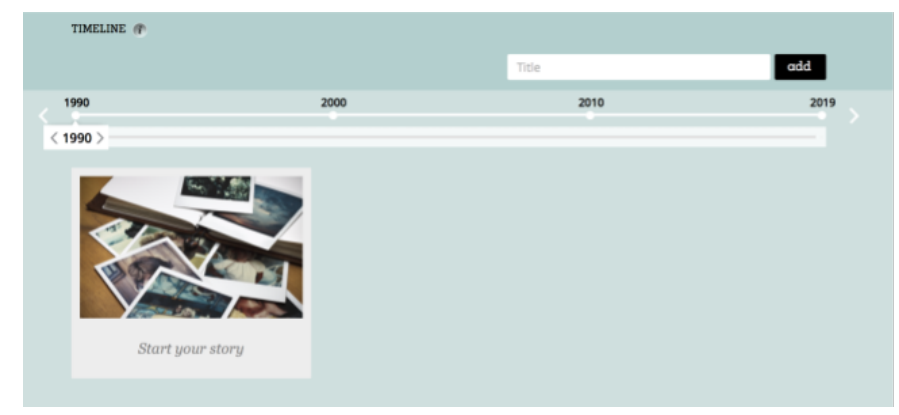

Fig. 13. Afternote timeline page. Image taken from site: https://www.afternote.com/timeline.

In 'preparation for your death', users can register wishes regarding their own funeral (Fig. 15). In addition, users can 


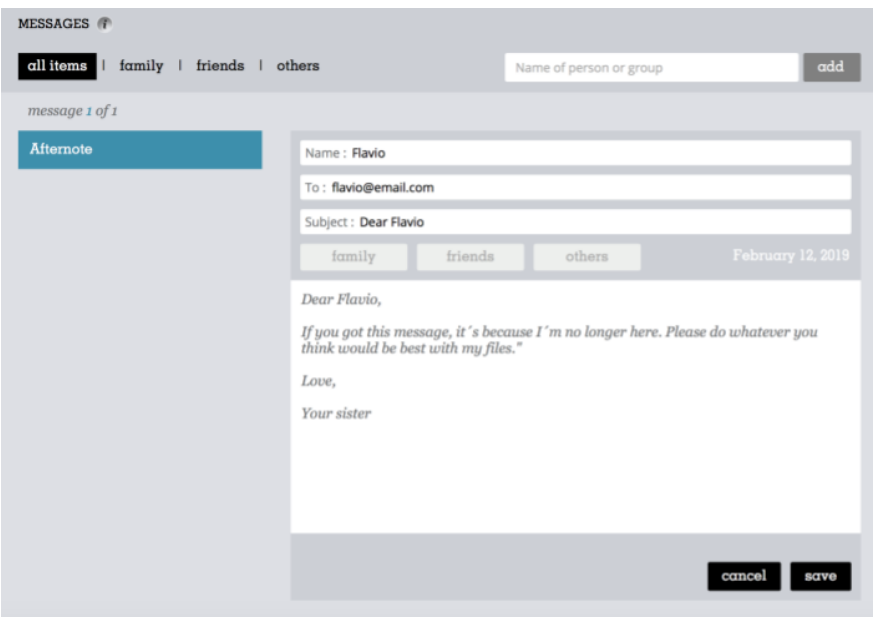

Fig. 14. Afternote messages page. Image taken from site: https://www.afternote.com/messages.

write messages that will be sent by e-mail to one or more recipients. Finally, they can leave instructions regarding each of their social media accounts, such as Facebook, Twitter, Google, Pinterest and others that the user may indicate (Fig. 16). However, users are warned not to enter personal account passwords even if it is possible to do so.

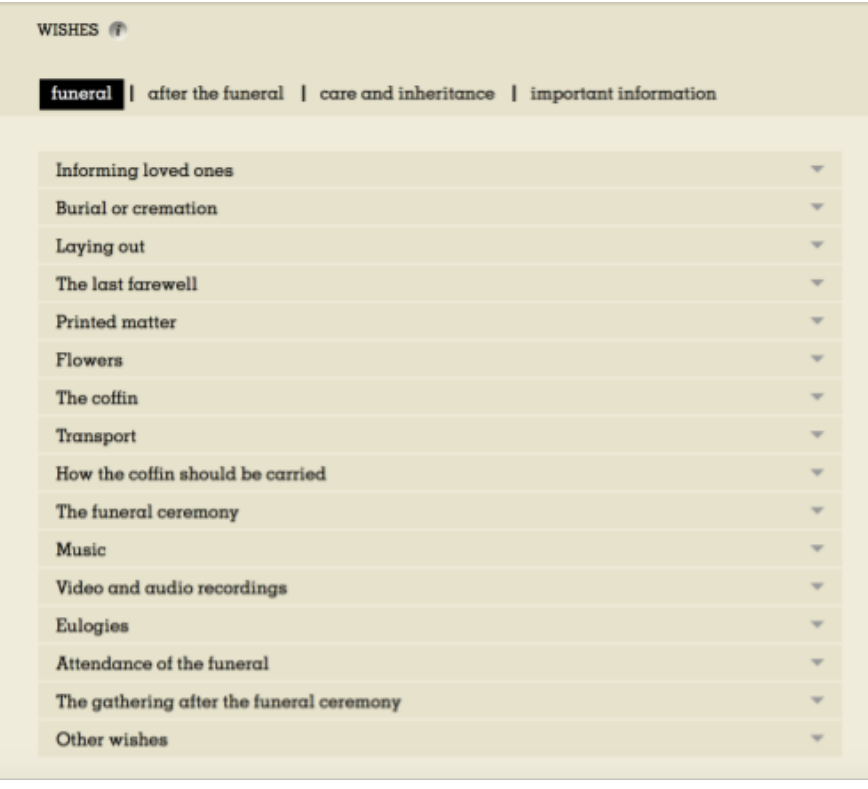

Fig. 15. Afternote wishes page. Image taken from site: https://www.afternote.com/wishes/funeral.

Users are required to indicate up to three trusted contacts to their account (denominated trustees in Afternote), who will be responsible for following users instructions (Fig. 17). In order to indicate a trustee, users send the person a request through the system. If the person accepts the role as the users' trustee he/she will be required to create an account in Afternote. The account owner is notified (by e-mail and within the system) once the trustee invitation is accepted or declined. Users may

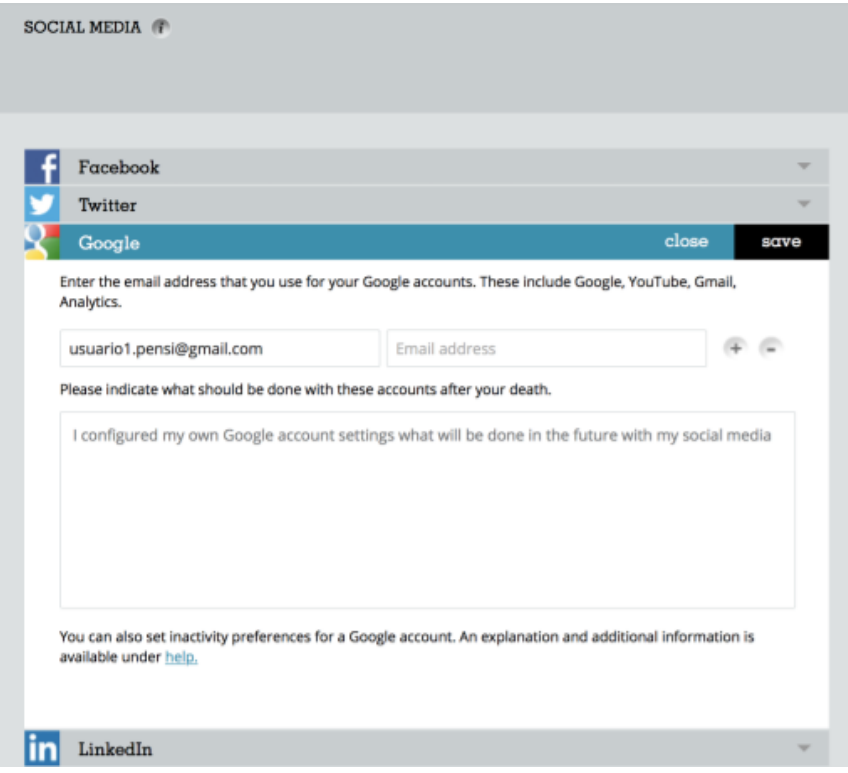

Fig. 16. Afternote social media page. Image taken from site: https://www.afternote.com/socialmedia.

replace or remove any of their trustees at any time. A trustee is not informed if the user has other trustees or who they are until the user passes away.

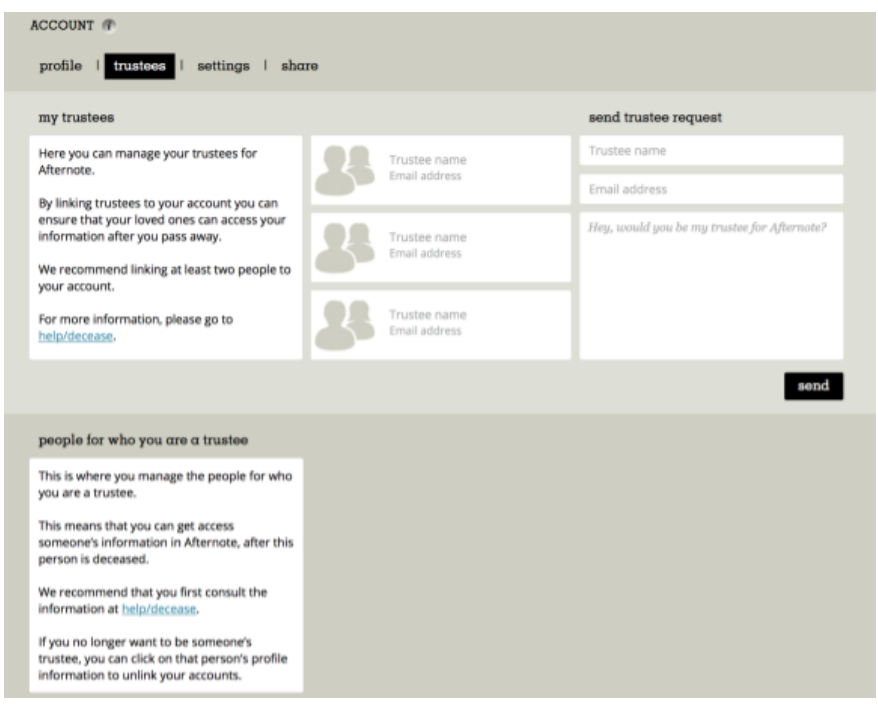

Fig. 17. Afternote trustees page. Image taken from site: https://www.afternote.com/Account/loadTrustees.

The trustee is expected to inform the system about the user's (account owner) death (this triggers the unlocking the user's account process, as can be seen in the message marked as 1 in Fig.18). When this happens, the user and the other trustees are notified, and if the information is not true, they will have up to seven hours to inform the system that the user is still alive. Once someone's death is confirmed, their account will be unlocked to their trustees (and only to them). They will have access to the user's information and wishes, but will not 
be able to change any information under any circumstances. Neither will they be able to see the content of the messages left or the e-mail addresses of their recipients, but they will be able to activate the system to send them (if not, they will be sent automatically in 7 days by the system). These messages will also be available to the recipients (through a link to the system) for a year. The trustees will have three months to check and download the user's information (before the account is permanently deleted), and in this period, they will also have the option to eternalize the account by turning it into a memorial page.

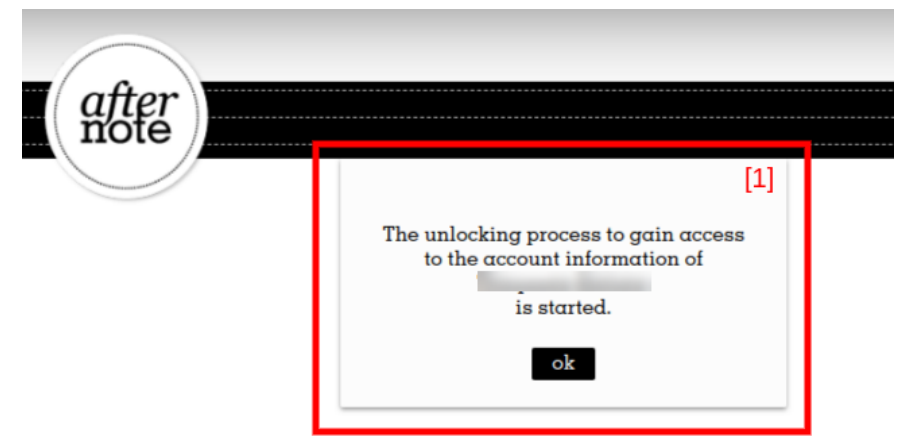

Fig. 18. Afternote message to unblock the user's account. Image adapted from https://www.afternote.com/.

Regarding the DiLeMa framework, Afternote makes use of the following interlocutors: user, beneficiaries, trusted contacts (called 'trustees') and the system itself. Therefore, Afternote defines all the interlocutors described in the framework. In the system, the user's inheritance includes the timeline which may contain a collection of photos with specific dates and descriptions of the moment depicted in each photo; the user's bucket list - which may have pictures and descriptions associated; as well as posthumous messages to be sent to heirs. A message may have as recipient a single heir or a group of heirs organized into categories: family, friends and others. Finally, Afternote allows users to leave what would be equivalent to a digital will, as well as other instructions (including instructions about their own funeral). Lastly, users can leave instructions specific to each of their social media accounts.

In Afternote, users are required to assign roles by inviting (up to three) people to take the role of a trustee, as well by nominating who are the heirs who will receive the messages to be sent. As for user status the system considers that a user may be active, uncertain, or inactive. The system relies on the trustee's notification of the user's death (external trigger) to activate the user's status verification process. Once the system is informed, the user's stats is changed to uncertain and users themselves, as well as other trustees are informed of the notification of death. If no one informs the system that the user is still active, the user's status is then changed to inactive and all trustees gain access to the user's profile. In Afternote, the only inheritance delivered are the messages left by the user, which are sent by e-mail to their recipients.

Regarding security mechanisms, the system explicitly informs users, on the help page, that it uses an SSL certificate and encryption for all personal information stored. It also states that Afternote does not have access to users' personal information because they are encrypted and, therefore, third parties will not have access either.

\section{B. Study 1 - Participants views on concepts}

In this section, we present the participants views in the study 1 who explored Afternote as users. Next, we describe results of our analysis of the first part of the interview which is organized in respect to the framework dimensions.

Interlocutors. Participants were asked who they perceived as the people involved in managing an account in Afternote, their roles and whether they thought there were any other roles that would be necessary. The purpose of this question was to verify which interlocutors described in the framework were regarded by users as interlocutors within the system. As mentioned, DiLeMa defines 4 interlocutors: the user managing his/her assets; trusted contacts; heirs and the system itself. All four of the interlocutors were identified by at least one of the participants. Participant P5 mentions all of them in his response 6 "Afternote, me [...], Fernanda and in the case here.... Flávio ${ }^{7}$, who will receive [everything] after I die”. In addition, all the participants identified users and trusted contacts as interlocutors; however, not all of them mentioned heirs and the system itself.

Some participants answered the questions more broadly, including as interlocutors their own relatives, and others included even the social media developers/managers. For instance, P3 said that "for the family you leave the assets and your children receive them" It was not clear whether $\mathrm{P} 3$ understood that he could register them as heirs, or if he referred to legal procedures adopted in the physical world (which currently do not clearly apply to the virtual world). P6, on his turn, also included his social media contacts as interlocutors: "besides me, the person I assigned to inform them [Afternote], in this case - Fernanda, and, indirectly, Flávio who will receive only one message and the people [contacts] in my social media accounts".

In regards to the responsibilities assigned to each interlocutor, participants had very different views. Some responsibilities were well understood, as is illustrated in P4's explanation about the trusted contact: "Fernanda will be the one to inform the system that I died, because that is how the system works and then system will act, sending messages to the registered emails [...]. The more general things will be done by Fernanda [...] For example, this timeline...I'm not sending anything to anyone. It's kind of mine, and Fernanda will see it [...] and, according to my wishes, she will show it. The social media, for example, Fernanda is who will decide. [...] and Flavio will

\footnotetext{
${ }^{6}$ All the interviews were conducted in their first language - Portuguese, so the quotes in the article were translated by the authors of the paper.

${ }^{7}$ Fernanda and Flávio are the names of the trusted contact and heir, respectively, presented in the task scenarios.
} 
only receive [the message]". On the other hand, for participant P4 it was not clear if the trusted contact was also an heir:

“Humm .. I don't know ... It is ... I think Flávio will also receive the file. Now I am not sure, if it's going to be just Fernanda. Flávio will receive it for sure, but now I don't know if Fernanda will also receive it. I don't know .. Now I'm thinking Fernanda and Flávio will receive it”. P5 explains his doubt about whether the heir also being a trusted contact (trustee): "I think Fernanda will take care of my things, Flávio will only receive some messages. I was not sure. If Flavio would also be able to take care of things, but I think he'll just get the message."

Finally, while most participants understood that the trusted contact would be the curator of the user's account and the heir would receive the messages, it was not clear to some of the participants if there is an overlap between the two roles, or exactly what is the differences between them.

Digital Assets. In terms of digital assets, most of the participants understood that digital artifacts manipulated by Afternote, such as pictures in the timeline, text messages and even social media accounts would be the assets managed by the system. When asked about the digital assets P1 says "Images and all social media accounts" and P3 also adds: "[...] and text, right?". This perception is in line with the designer's proposal described in the analysis presented by SIM. Nonetheless, some of the participants took a wider perspective when thinking about management.

Afternote allows users to register the accounts they have in other systems and include instructions on what they would like to be done in relation to each of them. Thus, this possibility may have motivated some participants to broaden their views about the digital assets managed by Afternote, and may have led them to think it could also manage content stored in other systems or social media sites. This view can be noticed in the responses given by P5 "In this case, it could be everything, right?! Because you can put everything in your Google Drive and here [in the Social Media section of the system] Google Drive was listed. So I guess that would be it, anything. If I have videos in Google Drive, if I have photos in Google Photos. Your own Facebook account." and P10, "Accounts that I have on some sites, the files I have within those accounts. Basically my accounts and the ownership of my accounts, and all they control. Photos on Drive, Facebook account, YouTube, bank account". Participant P3 included even the files on his own computer "Social Media. The files I own. Everything that I can access from my computer. Photos and files". However, he did not explain how he believed his heirs would gain access to all the content mentioned. At any rate, this view was not shared by other participants, as can be seen in P7's explanation of " Only things that are online. Google, all social media, Facebook... The things that are on my computer nobody will be able to manage if it (computer) has a password.".

Role Assignment. An important step users have to take when managing their digital legacy in a DLMS is to assign people to the other interlocutors' roles. To do so, users must understand the process defined by the system to make the assignment. Thus, the interview explored questions about the process of requesting someone to take the role of a trustee and the relevance of inviting or notifying that person previously.

Everyone understood correctly that the request would be made through the Afternote system, that would then send an e-mail inviting the person to become a trustee. Participant P9 thought the process was easy to understand: "The process is simple, you log in into your account and there is the dashboard where you enter the name and e-mail of the person you would like to manage your account afterwards and you leave a message for this person [...] After asking Fernanda to be responsible for informing the system about my death, Fernanda, who also needs to have an Afternote account, should accept my request or not". Although P9 understood that a trusted contact would also need to have an account in the system, this was not clear to everyone, as the P8 response illustrates: "What I did not understand is how the person will tell the system that I passed [died]”.

Several participants assumed (correctly) that Afternote would send a link in the e-mail message that would allow the person to accept or decline the invitation to become a trustee. Participant P10 stated that "The system will e-mail you [trusted contact] a link and you have to accept it". It is worth noting, that in their exploration of the system there was no information about how the system would allow people to accept the invitation, their answers were probably based on previous experiences with other kind of systems.

All of the participants considered extremely relevant that the trustee should be invited to take the role and agree to it before being given the responsibility of informing the system of a user's death. Both P7 and P8 still explained other issues they believed required the person to accept the trustee role. P7 states "certainly ... because sometimes I choose a single trustee and the person is not willing to take the role when I die" and P8 presents another concern when she says: "She (trustee) needs to know that she has this responsibility. That is not a simple little thing, it is a lot. There's even a place to see financial accounts, then it gets complicated."

User Status. In addition, we investigated whether the participants knew how the system would deliver the digital assets to the beneficiaries, who would have access to each of the contents and when the delivery would take place. According to the framework dimensions, the verification of the user's status is the process that a DLMS uses to determine whether the account owner is still using the account or whether the inheritance should be released. Only participant P7 understood how the system handles this verification process. He explains: " when I die, one of my trustees will access my account and will start a process informing the system that I died. If no one denies this information in seven hours, then the system will understand that I actually died and will release my data for all my trustees. Now, if someone says I didn't die, it will cancel the process. Releasing the data means that everything that I have registered on the site and that should be delivered. It is worth mentioning that the probable reason why P7 was able to understand well the process (while the other participants 
did not) was that during the period of free exploration of the system, P7 decided to read the help system (help menu), none of the others accessed these explanations.

Other participants, such as P2, for example, did not understand the main DLMS procedure: " how will the system guess you died and send [the messages]? [...] I don't know [...] this was not very clear to me ". P1 stated that some there should be a verification process, but she was not sure how it worked: "the problem is to tell when the person [the owner of the account] died. From the moment that the person died and the system recognizes it, [...] I think there is something like being inactive and such in some social networks". P4 also realizes that there should be some inactivity verification process, but he only raises a few assumptions: "May be there is a reminder every year, every month: 'Hey, is your brother still alive?' ".

Inheritance Delivery. Regarding how the system makes the digital assets available to the heirs, the participants were divided between e-mail delivery and availability through the system itself. P7 realized that the digital assets stored in the system would be handled differently. According to P7, only trustees would have access: "for example, my timeline and my posthumous messages should be sent, my wishes should be visible to the people who can see [the trustees]. My bucket list too. I think the person will get an e-mail saying, 'Hey, someone you were trustee for has died, you have to go to the site and take a look.' [...] here you have notifications, so I think it will appear in the notifications for the person to go somewhere, a page that has all the users information of he/she has right to see."

The points regarding the responsibilities or rights of the interlocutors that were not clear to the participants became evident when they talked about the inheritance. It was not clear to the participants how trustees would gain access to the digital legacy, what they will receive as digital assets, what exactly are they expected to do (if they are the heirs, if they are responsible for fulfilling the user's wishes or if they inherit the user's account). Many of their answers illustrate the doubts they had. P1: "the trustee will probably get an email informing him what he will receive, because he knows the person has died. It's probably not an e-mail such as 'that guy died'. It's probably an e-mail explaining that the person will have access to someone's social media because this someone died.". P3: "If it's Facebook, this person will receive a new password, different from the one I was using.". P4 had a better understanding of how things would work: "from what I understood, in the case of timeline, the person (trustee) will be able to see the photo and what I did each day. The social network... I was kind of thinking about it from the beginning, handing out my password, [...] in Facebook, for example, I could leave as instruction the Facebook password: "my password is this and I need that you do that". P9: "I think the person I made responsible could log in and see what I'm seeing here now. The system probably does not e-mail everything in a compressed file. It only gives you [trustee] access and then you save whatever you want to save."

Participant P2 did not seem to understand well how the system would work. She believed that Afternote would be able to access the contents of his social media, and also manage it as a digital legacy: For example, if I put my Facebook account here, I do not understand if it's going to tell the person: 'Look, here is the password and you can go there and see things', or if he's going to make a packet and send that packet to the person showing: 'These here were the photos she stored and this is what she said...at such time. This is what she liked the most or did not like'",.

Security. We also asked participants about the security aspects of the system and whether they would trust that the digital assets would be delivered as planned. Security mechanisms refer to the features that DLMSs must adopt to ensure the trustworthiness of the data being inherited and the privacy of the account owner.

Participants P9, P6, P4, P3, and P1 said they would trust the system because: (i) they would not include sensitive information in the system; (ii) of the process involved in including the digital assets; and (iii) of the trusted contacts. In P9's view, "the system gives you the option to add the things you want, the way you want them and write what you want. So I think it's all going to be there the way I left it". " P6 states "I imagined a trustworthy person at first, and the rest is all here in the system that I and that person would have access to" but he also complemented saying he would trust the DLMS because he would not insert any sensitive information into the system: "I'm not putting my bank account. So, if anything happened regarding security, there wouldn't be a problem".

However, this perspective is not shared by all participants. P2, who did not quite understand what the inheritance would be, was unsure about managing social media: "I do not want them to see my Facebook messages, I'd be worried. There would have to be a limit". P7, in turn, expressed concern about security in data delivery: "I would be concerned about leaking my personal information" and considers there would be ways to improve this security: "a link through the system is more secure than sending it directly to person's e-mail”.

Finally, when discussing user status we were able to conclude that most participants did not fully understand the process that leads the system to define the user as inactive. This point was reflected in security, when P10, P8, and P5 were concerned about the system being notified falsely that the user had died and the information being delivered ahead of time. P10 clarifies that if "if somebody I trusted pretended that I died, but I had not died. There should be validation from the Government". P8 states that he would have to rely not only on the system but also on the person he chose to be the trusted contact "it will not depend much on the system, it will depend more on the person I have registered [...] What if the person says that I died before I do and accesses my things?"

\section{Research Question 1 Analysis : Users Understanding of DLMS Concepts}

The systematic analysis of Afternote using SIM + framework dimensions allowed us to reconstruct the designers' 
decisions regarding each of the concepts. By contrasting the reconstruction of the designers' intended meta-message to users understanding we are able to discuss what concepts and aspects of the system users grasped and the ones that were not clear to them.

We noticed that all interlocutors described in the framework (system, users, trusted contacts and heirs) were identified by at least one of the participants. Only one participant explicitly included the system as interlocutor. However, some of the others noticed its active role in the communication, as they named the system as responsible for intermediating the users' invitation to someone to become a trustee, as well as for the inheritance delivery. All participants identified the user and the trusted contact as interlocutors. Notice that people who take these roles are the ones who need an account in the system, and interact directly with it. The heir, on the other hand, interacts indirectly with the system - does not need an account and only receives messages sent by the user through the system. Probably for that reason, not all of participants indicated heirs as interlocutors of the system. Participants understood the different roles in general, and they might not have indicated them as interlocutors, as they have different interaction levels within the system. One aspect that could be more problematic and could impact users decisions about their legacy, and use of the system, was that not all participants understood clearly the different responsibilities that would be expected of the trustee and heirs, nor exactly which content each role would have access to.

Regarding the digital assets, participants understood well most of them. However, the possibility to leave instructions for each social media account was confusing to many of the participants. The designers' intention is that for each social media account users could leave instructions (e.g. represented by a text) stating their wishes regarding the specific account, if they wished to. While some of the participants understood it correctly, others thought it meant giving the trustee access to their social media accounts (and their contents), and some went so far as to consider that Afternote itself would access the content in these accounts and even process it to send a summary or overview to the heirs. These misunderstandings were a cause of concern for some of the participants, that worried about the privacy of their content in their social media accounts.

All the participants understood that Afternote took into consideration the users' status (active or inactive), in order to be able to identify when it was time to fulfill the user's wishes. Most participants understood that the trustee was the one responsible for informing the system about the user's death. However, only one participant (P7), who spontaneously decided to read the help system was able to understand how the status verification process worked. Many of the others who did not understand the process, expressed their concerns regarding the possibility of a false notification to the system aimed at gaining access to the user's information inappropriately.

Based on our analysis, we can notice that participants identified the existing dimensions and in general the values the had been assigned in Afternote. However, participants had a more difficult time understanding correctly the dynamic signs that represented the future interaction of the system - that is, how some processes of the system would actually work. As mentioned, some participants were not clear about how the user status verification process worked, who (heirs or trustees) would have access to exactly what, and what level of access they would be giving to their social media accounts and even content.

These misunderstandings could represent a problem to the adoption and use of Afternote specifically, as well as other DLMS. If users are not sure they understand the future actions of the system to be made possible based on their decisions, they may feel insecure and prefer not to grant access to anything at all. It could also have an opposite effect, that would be that the people the users intended to gain access to some content would not be the ones to get it. Although, this might be difficult to identify - as the users would no longer be available to express their wishes, ethically designers should work not to let this scenario be a plausible one. Furthermore, it could be the source of a number of legal issues to the designers, trustees and heirs involved.

\section{RESUlTS - USERS' EXPERIENCES WITH DIFFERENT DLMS ROLES}

In this section, we present our results and discussion regarding our second research question, that investigates the participants perspectives and experiences in the distinct roles they can take within a DLMS. The motivation for analyzing this aspect is because we expect young adults who have technology ingrained in their lives, and generate/store so many digital assets to eventually become users (account owner's) of DLMS. We could also argue, that most of them would even have a higher chance of taking a role of a trusted contact for someone close at some point, or even becoming an heir. Thus, exploring their perspective on these roles is relevant to be able to analyze existing DLMS solutions and consider how to advance this technology.

The analyses of the different perspectives were based on the results of user studies 1 and 2. As described in the Methodology Section, both studies involved users exploration (directly or indirectly) of the system, and an interview about their views on Afternote from a specific perspective - account owners or trustees. In both interviews we asked them about their views on taking the role of an heir as well.

We next present the results of the interview of user study 1 , regarding the questions about the participants experience in the role of the user (account owner). Then we present the results of the interview of the user study 2, that explores participants view in the role of the trustee. Finally, we discuss the results regarding the overall user experience with the system.

\section{A. Study 1 Participants' Experience as Account Owners}

In this subsection we explore the perceptions and experience of the participants based on their interaction with Afternote through the user's (account owner's) perspective. The first 
aspect explored with participants was their perspective on their digital assets and their potential value to someone in the future. All of the participants said they believed they did not have a complete view of all their digital assets, they considered they probably had more than they would expect. For instance, P9 says "[...] its too much stuff. There are things there that I don't even remember.".

Three of the ten participants considered that their possessions would be of no use to others in the future, whereas the other participants believe that they would have sentimental and affective value. P2 reported: "to be honest, I think my digital items will not be of any use”. P4 is certain that some of his digital assets may interest his loved ones: "Not monetary value. Sentimental value, sentimental value only to my family and friends". P8 discusses scenarios where he thinks someone's legacy might have a higher value: “[...] thinking from the point of view of someone working on an important project, then it would be very useful. In my case, I am a mere mortal, so I do not know; but sometimes the person is working on a very interesting research and dies before finishing it, then it would be cool". Only two of the participants said they had items with financial value. P10 mentioned "items in games that you can sell in real life, but it is not very relevant" and P8: "my bank account".

We asked the participants if they had ever thought about what would happen to all of their digital content after their death and how they would feel if they received a digital inheritance of a loved one. Many of the participants said that they had never thought about what would happen to their accounts and their digital items after their own death. Others commented that they had thought about it at some point. For instance, P10 commented that "I thought it [the data] would be there forever until someone discovered that I died and even then I think they would not have the heart to delete it”. Regarding the data, P2 and P8 expressed concern about access to their personal data, as illustrated in their speeches: P2: "This issue of 'What will people see?'. Because there are some things I wouldn't want anyone to see."; and P8 "I worry that there is a lot of information there for anyone who wants it to get it and after I die it will get even easier because I will not be in control anymore”. P5 worried that all of his digital assets would be lost: "somewhere in my room I have all my passwords, then someone would find my passwords and have access to those photos. But if no one found them [the passwords], it would be lost.".

We also asked the participants about their experience with Afternote during the study, and how they felt about adding and organizing their Digital Legacy to be delivered to someone in the future, and whether the idea struck them as odd or unusual. Participants felt very differently about the experience. Three of the participants did not think the situation was uncomfortable (to organize the entire digital heritage). P2 commented: "Actually, I think it should be something that everyone should do. Now, I am thinking that everyone should stop to think what really matters. What should I leave or not.". P9 commented that this topic (postmortem Digital Legacy) being a new one, might make people uncomfortable. "We never think about this possibility being so young. At first, because it's not very common and it is kind of weird, but when it gets more common, people will deal with it more naturally. P6 points out that for him the main issue is that it would be very time consuming: "It did not cause bad feelings, but I think that the person has to be on the mood to access the site all the time and 'Oh! Today I'm going to include this here because I think it's important after I die". However, the other participants felt that the interaction had a heavier emotional toll associated to it. P3 states: "It seemed strange and unusual. Sad even...”. P7 still complete: "There is no way I can navigate this site and not think that one day I'm going to die and that everything that I do today doesn't have any value”. P10 felt that it was: "Very uncomfortable. Very weird.".

Regarding how they would feel if they received the digital legacy left by a loved one as an inheritance, three reported that they would certainly feel good because they were selected by the person to receive it, as illustrated by P2: "I would probably feel good because I would feel that I was chosen by that person to deal with it [the digital legacy].”. However, P6 and P8 pointed out that they would not necessarily want to receive all the digital assets of the person, only what was relevant or related to themselves - P6: "It's kind of other people's trash, let's put it that way. Because it's a lot of things. Of course there are some things that are relevant, but imagine receiving all the silly stuff... But if it's something useful thing, okay, I would even feel honored!" and P8: "I think it would be cool if it was of my interest".

Others were more reluctant about the situation. Some of them mentioned that the moment when they received the legacy after the person's death could influence how they felt. However, there were different views on when it would be the best or more appropriate moment. For instance, P7 thought that getting the digital inheritance shortly after the person's death would be easier - "Years...I don't know. Sometimes it was a death that affected you a lot and it took you a long time to get over it and get well, and one day you wake up and when you open your e-mail, a lot of photos of that person who died. How awful! I don't know, but right after [the person's death] would be ok.". P5, on his turn, had an opposite view: "the person died today and tomorrow I am getting all the person's photos, I think it could be a very heavy thing emotionally, but maybe years later [it would be ok].”. Some participants felt that receiving the digital legacy could generate different emotions. P10 expressed his doubts: "I would be emotional, but I do not know what kind of emotion I would have, whether it would be good or sad". P9 reported that he might feel uncomfortable at first, but later would feel good about having memories of the loved ones: "At first it's going to be kind of sad, but over time it's cool to keep this as mementos. Initially I might not feel very comfortable, because it's still very recent, it could be kind of painful, but then I think it would be good to see these things [digital assets].”.

To conclude, we asked participants if they would use a system like Afternote or any other that would allow them 
to organize their digital data to be delivered posthumously. Again, participants had contradictory views on the use of the system. P1, P2, P4, P7, P8 and P9 stated that they would use such a system, as illustrated by P2: "I would probably use it, specially because I had already thought about it. I just didn't know where I could put it all together in an easier way. In a way that would be easy for the other person to get it, but I'd probably use it. [...] I would use Afternote, but I would have to sit here, read everything to know who will receive it, what day and how can I make choices.". The other participants considered they probably would not use DLMS. For instance, P3 stated that being so young it was not yet time to think about digital inheritance: "I don't think I'd use it because we consider ourselves too young for this. I wouldn't be proactive enough to do it, but in a given situation I could even do it.". In the same direction, P6 said he would only use it in case of great need, "humm... only if I realized that something was really worthwhile."

\section{B. Study 2 Participants' Experience as Trustees}

In this subsection, we investigate the perception and views of the participants of study 2 with Afternote, in the perspective of a trustee. Although participants did not interact directly with the system, they went through the interfaces and watched videos of the interaction of a trustee with the system. The interview followed the system exploration with the participants.

The first issue explored was whether they would accept the role of someone's trustee and for whom. Most participants said they would accept the role, especially if it were for a family member or friend. All participants (except P1) answered positively in a similar fashion to one another, declaring they would be trustees to close people. As an example, P4's statement: "Probably, to relatives and close friends". Only $\mathrm{P} 1$ said she would not accept to be anyone's trustee, in any circumstances due to the burden of such responsibility.

In Afternote, once the account owner dies, the trustees are the ones responsible for fulfilling their wishes about the future of their digital legacy. When asked if they would feel well in being the one responsible to manage these digital assets from the account owner, participants expressed very different sentiments. Whereas most participants said they would feel okay with it, or even honored for having been chosen by the account owners, others expressed it would depend on who the account owner was. P1 mentions she would feel weird whomever it was, as it would feel as if someone "Is giving orders from their tomb. That is absurd!'”

During Afternote's video presentation, one of the videos showed the process of adding a Trustee, which involved an invitation being sent, giving the person the opportunity to accept the role or not. When asked about if it was important that the request be made beforehand ${ }^{8}$, all participants were very clear in saying that it was very important that the request to be a trustee is made beforehand. Three of them thought

\footnotetext{
${ }^{8}$ Not all DLMS requires the trusted contact to be invited and accept the role. In some of them, the trusted contact can just be nominated and only find out about it once the account owner dies [29].
}

that even just the email invitation would not be enough, and they thought it would require a face-to-face conversation. In this direction P5 says "matters of post-mortem or post-life, as you want to call it, are very delicate. I think a conversation is necessary for that.".

Regarding the invitation to become a trustee, we asked participants if they would feel comfortable to decline the invitation. Most of the participants said they would be okay to say 'no'. P5 stresses that "Feel comfortable? No. But I would say no, you know, to some people, probably. But feeling comfortable with it is something else". P7 commented if it were a loved one, he would always accept. We also asked if they decided to decline the invitation, whether they would do it through the system or in person. Most people believed they would feel they should talk to the account owner in person. P1 and P4 said that decision would depend on who was the person making the invitation. P4 also said he would take into account whether the person had talked to him about it in person, or just sent the inviation through the system.

Once someone accepts the role as a trustee, this person is expected to notify the system of the account owner's death, and once the account becomes unblocked to be the one responsible to fulfill the user's wishes. In our interview, we asked participants how they felt about these tasks. Regarding informing the system of someone's death five of the seven participants (P1, P2, P4, P6 and P7) thought it would be something they felt okay with. P7 points out that it might be too much responsibility for just one person, and it would probably be better to have more than one trustee. P4 explains why he thought it would not have much cost to him "It's part of the system...someone's death is something hard to go through, but in regards to informing the death to a system that has no... It's not a person with whom I have to talk, it's not a person who has memories of that person, it doesn't have an emotional weight. Hmmm, it's not someone who I have to interact with, who will react negatively to it.". Nonetheless, P3 and P5 still thought it would be difficult for them to inform the system.

As for when they would inform the system, once again participants had very different views. P1 and P5 would inform the system as soon as possible. P5 pointed out that there could be wishes regarding the funeral, so it would be important to do it quickly. The others said they would probably wait sometime and gave different reasons. For instance, P6 mentions she would probably be grieving the loss of a loved one, and might not think about the system right away. P7 thought he would probably wait to be able to take a careful look at what was being asked, organize what was needed and make sure he would make the "right decisions". P4 took into consideration his relationship to the account owner. If he was next of kin, he would fulfill the person's wishes. If not, he would check with the person's family first.

We also inquired the participants if they would feel obligated to honor the deceased's wishes indicated in the system. All of the participants said in principle they would try to honor the account owner's wishes. However, they said they 
would also take into account what was being asked, and if they would feel comfortable with the request. P5 expresses the overall view: "Yeah, morally, yes. Also... It's a little selfish, but it would also depend on what the wishes were. Because, we never know what the person would ask, but... So, I guess it would depend a little on priciples. But, overall, yes, I would do all that was necessary.”. P7 also expresses a concern regarding the amount of things that would be asked, and would consider asking other to help: "If I though I would not be able to do it, I'd share the tasks. I'd take the most important ones for myself and pass others to family and friends. But, I would prioritize [which wishes to honor].”.

As in the interview in study 1, we also explored participants' views on becoming an heir to someone's digital legacy. Most of the participants had a positive feeling about being an heir, and thought that it could help them through the grieving period, and could help them have an overview of someone's life or a memento from that person. P3 points out that, altough she would like to receive the digital legacy, it could take an emotional toll - P3: "Hmm, I think I'd be happy, but I think it would be..., kind of..., hmmm.... In a moment like this, recent of... passing away, it would be, hmmm... emotionally heavy. Not because it's bad, but simply because it is really heavy. A heavy emotional toll.". On the other hand, P1 and $\mathrm{P} 2$ pointed to some restrictions they would have in receiving someone's legacy. P1 would not like to get overwhelmed with too many digital artifacts: "Well, I wouldn't feel bothered, but also I wouldn't be particularly happy getting 500 photos of someone who died.", whereas P2 thought it would be too much responsibility: "Not much [feel well about it]. It's a responsibility I don't feel ready to take on. Independently of the person. I feel more comfortable being the lawyer, say, then the heir, you see?"

Finally, we asked participants how they felt towards the topic of thinking about the future of digital legacy. Most of the participants felt it was rather strange, but explained that it was probably because it was new to them and unusual. Participant P2 even compares it to a fiction series: "Huh, so, up to this moment, I had never heard of it, so a little [strange]. A little strange. [...] Because I had never heard of it. But it sounds, kind of like 'Black Mirror"'? Nonetheless, most of them thought it made sense, as illustrated by P4: "It's not something you think much about, it something very recent, and kind of unusual, but all that strange.[...] Because, I don't know, if it [the content] stays there its interesting to have some development for that afterwards, and that its not just lost forever.", P5 also comments that although it is strange, it makes sense since the internet is so ingrained in today's society.

Some of the participants raised some of the issues they thought were more troublesome about DLMS. P1 said she thought it was uncommon, since she believed would not be of interest to the heirs. P3 thought some of Afternote's

\footnotetext{
${ }^{9}$ Black Mirror is a British science fiction TV series which examines unanticipated consequences of technology in society. (See: https://www.netflix.com/br-en/title/70264888 - Last visited Feb. 2019).
}

features were interesting (e.g. being able to register your wishes regarding your funeral), whereas others not so much. P6 and P7 were more troubled by the emotional aspect of it. P6 thought not everyone would feel comfortable being a trustee. In the same direction, P7 said he would be okay to fulfill the person's wishes, but not to make decisions in someone's behalf.

\section{Research Question 2 Analysis: Experiences with Different DLMS Roles}

The analysis of the results of the interviews of the 2 studies allows us to discuss the experience and perception that young adults had with the system as a whole, considering all the possible roles. Participants of study 1 reported not having a precise view of all the digital artifacts they had stored. Nonetheless, in both studies young adults believed their digital artifacts did not have much value, some of them thought it would have no value at all. Many of them mentioned that they thought that digital artifacts mainly would have an emotional value to people close to them, either when talking about their own digital assets or those of other people (thinking about the role of an heir). Two participants in the first study (P8 and P10) mentioned they had digital assets that they considered to have a financial value, and participant 8 also mentioned that he considered that someone's work (not talking about his own) could have value - for instance, an unfinished research.

Participants of both studies believed it makes sense to think about the future of one's digital legacy after their death. However, many of them were thinking about this post-mortem scenario for the first time, and thought it was 'weird' or uncomfortable to think about it. For all of the three roles considered (account owner, trustee and heir) participants mentioned there would be an emotional cost associated to using the system. In the role of the account owner, participants believed that thinking about their own death and about what was the value of their digital assets would not be easy. For the trustee role, they considered that accepting the role would be a responsibility in itself, and then the trustee tasks themselves could be emotionally heavy, as well. Nonetheless, most of them said they would take the role if the account owner was someone close (family or close friend). Even for the role of an heir, they thought that although most of them would like to receive a loved one's digital legacy, it could be difficult depending of how they were dealing with their grief when they received it.

The emotional cost was not the only one that worried participants. Once again, they raised other costs associated to each of the roles. For the account owner's role, some of them mentioned that keeping the account updated with what a person would like to leave others would be too time consuming, and they might not consider worth it (unless there were specific conditions that would make them think it was worthwhile). As trustees, they worried about how much work would be required of them, as well as what kind of things the account owner would ask of them, and mentioned that there might be things they would not be willing to do. Finally, 
as heirs they worried that they would receive a very large amount of digital artifacts and that many of them would be meaningless (to them).

\section{FINAL REMARKS}

In this paper we set out to explore young adults' (ages between 18 and 24) perspectives on Digital Legacy Management Systems (DLMS). Our goal was twofold: investigate their understanding of new concepts introduced by this domain, described in DiLeMa framework; as well as their experience in the different roles involved in DLMS. The reason why we chose this specific profile, was that young adults are digital natives who throughout their lives most likely will collect a large number of digital artifacts, that they could consider leaving to others as their legacy upon their deaths.

Regarding the young adults understanding, our results show that they were able to understand the new concepts introduced by DLMS. We used the DiLeMa framework to generate a reconstruction of the meaning being conveyed by Afternote designers regarding each dimension. Being able to use the DiLeMa framework to structure and contrast expert and users perception of the new concepts, contributes to previous works intended to consolidate the framework itself [13].

Understanding future interactive paths, and how the account owner's decisions impacted other roles actions within the system was more of a challenge. Some of the participants that took an account owner's perspective did not clearly understand what content would be seen after their death by the trustee or heir (although, they did understand the concept of the roles). Most of them had trouble understanding the status verification process (how the system would change the user's status from active to inactive). Only one participant (P7), who spontaneously read part of the help system while exploring Afternote, understood it.

The participants exploring the system as trustees were exposed to a video that simulated a trustee's interaction. The videos allowed them to see how different steps of the process of notifying the system of a death of an account owner worked, and probably explains why it was easier for them to understand the process. Previous works have indicated that one of the challenges for users to interact with systems that involves configuration that will only come into effect over time, is to support them in anticipating the future interaction [30]. Digital legacy management is a domain in which users having a clear understanding of the impacts of their decisions is especially relevant [29], [31]. Although, the participants that simulated the trustee role were able to better understand the future interaction that would be required by watching a simulation (not simulating per se) seems to reinforce researches that show that simulation is often a better solution for users to understand the possible interactive paths involved than just the textual explanations (metalinguistic signs) [32]-[34].

Interviews with participants of both studies indicated that young adults considered their digital assets could have sentimental value to others, but a few of them thought their assets might not have any value at all. Two of them mentioned they had digital assets that held financial value, and one participant thought someone's work could have value (but did not consider it to be his case). One could argue that this low value associated by young adults could be a problem to DLMS. However, we argue that this low value has less to do with intrinsic value of digital assets, and more with young adults stage in life. As they are in the very beginning of their professional and adult life, they probably have not yet generated professional work that might be valuable to other colleagues, or even been able to acquire digital assets that could have financial value.

Furthermore, Afternote does not allow users to upload files or different types of content, only photos to be associated to the timeline and bucket list. This could also have led participants to only think about these kinds of artifacts, as the interview was conducted after their exploration of the system. Among the digital assets that Afternote does allow account owners to express their wishes about is their social media accounts. However, participants that interacted as account owners had different interpretations about what exactly it meant to inform their login email account to the trustee through Afternote. Some of them thought it would mean that trustees would have access to their account, and one even thought that Afternote would be able to process the content in the social media system and generate summaries or highlights to be sent to heirs. These misinterpretations caused concerns on these participants. Although participants did not think that their digital assets could have much value, some of them were clearly worried about the privacy of their content, and stated that they did not want shared with anyone some of the things in their social media accounts.

One issue that was raised by participants during the interviews was the cost associated with using Afternote. The emotional cost is associated to death itself, as well as having to make decisions about and deal with one's own death, or that of a loved one. Thus, this emotional cost, is inherent to the domain in hand. However, the other costs that were raised by participants could be considered in the design of such systems. One of the issues raised is the cost associated to curating one's digital artifacts. As mentioned, in Afternote account owners can only include photos and textual messages, but not other digital artifacts. Even so, participants thought it would be too time consuming to configure the system. Some of them mentioned that this would be something to do throughout life, always updating the information you would like to leave to others. Thus, although some works have explored virtual possessions and how to pass them down [1], [35], it would be interesting to further research how one could curate their digital possessions throughout life to minimize the cost of managing their digital legacy.

Regarding the trustee and heir perspectives, the costs identified were more related to the decisions of the account owner. Although the system cannot interfere with one's final wishes, it could allow an account owner to better organize their wishes, for instance adding more trustees and being able to assign specific tasks to each one (or a subset) of them. 
One of the aspects many participants took into account when discussing the emotional cost associated to the use of the system was the moment in which they received the information (heir) or would have to interact with the system (trustee). However, there was no consensus on participants views of what would be the best moment to do it, it varied from person to person. Thus, one aspect that could be investigated is if this could also be something the account owner could configure or, in some cases, inform the trustee. The account owners, knowing their heirs, could be able to set a specific period of time after their death for the system to send their digital assets to each of the heirs. Also, regarding the trustees, it might be important to inform them when they would be expected to inform the system of the owner's passing. For instance, some of them said they would wait 2 or more days to inform the system. However, if the account owner had left wishes regarding the funeral, when the trustee came upon the instructions, it might be too late. Of course, designers should weigh the cost versus benefits, as more configuration would also increase the cost of using the system, which was already considered high.

Finally, as a future work, it would be interesting to conduct a similar study with users of other age groups. Although the young adults represent the digital natives, they tend not to think about their own deaths. People who have children and possessions (virtual, or even material) would probably be more motivated to think about what to leave to loved ones, or the destination of such possessions. Thus, these different perspectives could also add to all the findings discussed in this paper for young adults.

\section{ACKNOWLEDGMENTS}

The authors thank all participants of the two user studies for their contribution to this work. We also thank CAPES and FAPEMIG for partially supporting this work. Finally, authors thank Carla Leitão for her discussion of the paper during IHC 2018 and the idea to explore the users' perspectives of different roles in the system.

\section{REFERENCES}

[1] W. Odom, J. Zimmerman, and J. Forlizzi, "Placelessness, spacelessness, and formlessness: Experiential qualities of virtual possessions," in Proceedings of the 2014 Conference on Designing Interactive Systems, DIS '14, (New York, NY, USA), pp. 985-994, ACM, 2014.

[2] C. Maciel and V. C. Pereira, Digital Legacy and Interaction: PostMortem Issues. Springer International Publishing, 2013.

[3] M. Massimi, W. Odom, R. Banks, and D. Kirk, "Matters of life and death: Locating the end of life in lifespan-oriented hci research," in Proceedings of the SIGCHI Conference on Human Factors in Computing Systems, CHI '11, (New York, NY, USA), pp. 987-996, ACM, 2011.

[4] The Digital Beyond, "Digital Death and Afterlife Online Services List I The Digital Beyond," 2018. Last accessed: November, 2018.

[5] J. de Oliveira, L. Amaral, L. P. Reis, and B. M. Faria, "A study on the need of digital heritage management plataforms," in Information Systems and Technologies (CISTI), 2016 11th Iberian Conference on, pp. 1-6, IEEE, 2016.

[6] M. Massimi and R. M. Baecker, "A death in the family: Opportunities for designing technologies for the bereaved," in Proceedings of the SIGCHI Conference on Human Factors in Computing Systems, CHI '10, (New York, NY, USA), pp. 1821-1830, ACM, 2010
[7] R. Gulotta, A. Kelliher, and J. Forlizzi, "Digital systems and the experience of legacy," in Proceedings of the 2017 Conference on Designing Interactive Systems, DIS '17, (New York, NY, USA), pp. 663-674, ACM, 2017.

[8] W. Jones, V. Bellotti, R. Capra, J. D. Dinneen, G. Mark, C. Marshall, K. Moffatt, J. Teevan, and M. Van Kleek, "For richer, for poorer, in sickness or in health...: The long-term management of personal information," in Proceedings of the 2016 CHI Conference Extended Abstracts on Human Factors in Computing Systems, CHI EA '16, (New York, NY, USA), pp. 3508-3515, ACM, 2016.

[9] V. Kaptelinin, "Making the case for an existential perspective in hci research on mortality and death," in Proceedings of the 2016 CHI Conference Extended Abstracts on Human Factors in Computing Systems, CHI EA '16, (New York, NY, USA), pp. 352-364, ACM, 2016.

[10] Instituto Brasileiro de Geografia e Estatística, "Pnad - acesso à internet e à televisão e posse de telefone móvel celular para uso pessoal,” 2016. Last accessed: May, 2018.

[11] F. Tempesta, F. H. S. Pereira, and R. O. Prates, "Young adults' perspective on managing digital legacy: An analytical and exploratory study," in Proceedings of the 17th Brazilian Symposium on Human Factors in Computing Systems, IHC 2018, (New York, NY, USA), Association for Computing Machinery, 2018.

[12] Afternote, "Online service to record your life story, funeral and legacy," 2018. Last accessed: May, 2018.

[13] F. H. S. Pereira and R. O. Prates, "A conceptual framework to design users digital legacy management systems," in Proceedings of the XVI Brazilian Symposium on Human Factors in Computing Systems, IHC 2017, (New York, NY, USA), pp. 1:1-1:10, ACM, 2017.

[14] F. H. S. Pereira, "Investigação sobre antecipação dos impactos da interação em sistemas de gerência de legado digital de usuários," 2017. Available in: http://www.bibliotecadigital.ufmg.br/dspace/handle/1843/ ESBF-AQRQHW. Last accessed: November, 2018.

[15] C. S. de Souza, C. F. Leitão, R. O. Prates, and E. J. da Silva, "The semiotic inspection method," in Proceedings of VII Brazilian Symposium on Human Factors in Computing Systems, IHC '06, (New York, NY, USA), pp. 148-157, ACM, 2006.

[16] M. C. C. Baranauskas, C. S. de Souza, and R. Pereira, "Grandihcbr: prospecção de grandes desafios de pesquisa em interação humanocomputador no brasil," in Companion Proceedings of the 11th Brazilian Symposium on Human Factors in Computing Systems, pp. 63-64, Brazilian Computer Society, 2012.

[17] C. Leitão, C. Maciel, L. S. G. Piccolo, L. Salgado, P. C. de Souza, R. Prates, R. Pereira, and V. C. Pereira, "Human values in hci: A challenge for the grandihc-br," in Proceedings of the XVI Brazilian Symposium on Human Factors in Computing Systems, IHC 2017, (New York, NY, USA), pp. 70:1-70:6, ACM, 2017.

[18] R. M. de Araujo, R. S. Maciel, and C. Boscarioli, "I GranDSI-BR Grandes Desafios de Pesquisa em Sistemas de Informação no Brasil 2016 a 2026," Relatório técnico, 67pg, 2017. ISBN 978-85-7669-359-8.

[19] A. D. Lopes, C. Maciel, and V. C. Pereira, "Recomendações para o design de memórias digitais na web social," in Proceedings of the 13th Brazilian Symposium on Human Factors in Computing Systems, IHC '14, (Porto Alegre, Brazil), pp. 275-284, Sociedade Brasileira de Computação, 2014.

[20] V. C. Pereira, C. Maciel, and C. F. Leitão, "The design of digital memorials: Scaffolds for multicultural communication based on a semiotic analysis of tombs," in Proceedings of the 15th Brazilian Symposium on Human Factors in Computer Systems, IHC '16, (New York, NY, USA), pp. 25:1-25:10, ACM, 2016.

[21] K. L. de Campos, T. Justi, C. Maciel, and V. C. Pereira, "Digital memorials: A proposal for data management beyond life," in Proceedings of the XVI Brazilian Symposium on Human Factors in Computing Systems, IHC 2017, (New York, NY, USA), pp. 23:1-23:10, ACM, 2017.

[22] S. Jamison-Powell, P. Briggs, S. Lawson, C. Linehan, K. Windle, and H. Gross, ""ps. i love you": Understanding the impact of posthumous digital messages," in Proceedings of the 2016 CHI Conference on Human Factors in Computing Systems, CHI '16, (New York, NY, USA), pp. 2920-2932, ACM, 2016.

[23] F. H. S. Pereira, R. O. Prates, C. Maciel, and V. C. Pereira, "Analysis of interaction anticipation and volitive aspects in digital posthumous communication systems," in Proceedings of the 15th Brazilian Symposium on Human Factors in Computer Systems, IHC '16, (New York, NY, USA), pp. 19:1-19:10, ACM, 2016. 
[24] DeadSocial, "DeadSocial - Prepare for Death Digitally \& Build Your Digital Legacy - DeadSocial - Digital Legacy Management," 2018. Last accessed: May, 2018.

[25] R. Gulotta, W. Odom, H. Faste, and J. Forlizzi, "Legacy in the age of the internet: Reflections on how interactive systems shape how we are remembered," in Proceedings of the 2014 Conference on Designing Interactive Systems, DIS '14, (New York, NY, USA), pp. 975-984, ACM, 2014.

[26] J. Pfister, “"this will cause a lot of work.": Coping with transferring files and passwords as part of a personal digital legacy," in Proceedings of the 2017 ACM Conference on Computer Supported Cooperative Work and Social Computing, CSCW '17, (New York, NY, USA), pp. 1123-1138, ACM, 2017.

[27] C. S. de Souza, The semiotic engineering of human-computer interaction. MIT press, 2005.

[28] C. S. de Souza and C. F. Leitão, Semiotic Engineering Methods for Scientific Research in HCI. Morgan \& Claypool, 2009.

[29] R. O. Prates, M. B. Rosson, and C. S. de Souza, "Analysis of configuration decision space over time: The google inactive manager account case," in Proceedings of the 15th Brazilian Symposium on Human Factors in Computing Systems, IHC '16, (New York, NY, USA), pp. 23:1-23:10, ACM, 2016.

[30] R. O. Prates, M. Rosson, and C. S. de Souza, "Interaction anticipation: Communicating impacts of groupware configuration settings to users," in End-User Development (P. Díaz, V. Pipek, C. Ardito, C. Jensen, I. Aedo, and A. Boden, eds.), vol. 9083 of Lecture Notes in Computer Science, pp. 192-197, Cham: Springer International Publishing, 2015.

[31] R. O. Prates, M. B. Rosson, and C. S. de Souza, "Making decisions about digital legacy with google's inactive account manager," in HumanComputer Interaction - INTERACT 2015. INTERACT 2015 (F. M. G. T. P. P. W. M. DAbascal J., Barbosa S., ed.), vol. 9296 of Lecture Notes in Computer Science, pp. 201-209, Springer, 2015.

[32] V. Wulf and B. Golombek, "Exploration environments: Concept and empirical evaluation," in Proceedings of the 2001 International ACM SIGGROUP Conference on Supporting Group Work, GROUP '01, (New York, NY, USA), pp. 107-116, ACM, 2001.

[33] M. P. Junior, S. I. d. R. Xavier, and R. O. Prates, "Investigating the use of a simulator to support users in anticipating impact of privacy settings in facebook," in Proceedings of the 18th International Conference on Supporting Group Work, GROUP '14, (New York, NY, USA), pp. 63-72, ACM, 2014.

[34] R. O. Prates, M. Rosson, and C. S. de Souza, "Analyzing the communicability of configuration decision space over time in collaborative systems through a case study," Journal on Interactive Systems - JIS, vol. 8, pp. 62-76, 2017.

[35] W. Odom, R. Banks, D. Kirk, R. Harper, S. Lindley, and A. Sellen, "Technology heirlooms?: Considerations for passing down and inheriting digital materials," in Proceedings of the SIGCHI Conference on Human Factors in Computing Systems, CHI '12, (New York, NY, USA), pp. 337-346, ACM, 2012. 